\title{
The prominent alteration in transcriptome and metabolome of Mycobacterium bovis BCG str. Tokyo 172 induced by vitamin $\mathrm{B}_{1}$
}

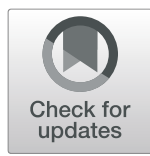

Ningning Song, Zhaoli Li, Ziyin Cui, Liping Chen, Yingying Cui, Guanghui Dang, Zhe Li, He Li and Siguo Liu*(D)

\begin{abstract}
Background: Vitamin $B_{1}\left(V_{B 1}\right)$ is a crucial dietary nutrient and essential cofactor for several key enzymes in the regulation of cellular and metabolic processes, and more importantly in the activation of immune system. To date, the precise role of $V_{B 1}$ in Mycobacterium tuberculosis remains to be fully understood.

Results: In this study, the transcriptional and metabolic profiles of $V_{B 1}$-treated Mycobacterium. bovis BCG were analyzed by RNA-sequencing and LC-MS (Liquid chromatography coupled to mass spectrometry). The selection of BCG strain was based on its common physiological features shared with M. tuberculosis. The results of cell growth assays demonstrated that $V_{B 1}$ inhibited the BCG growth rate in vitro. Transcriptomic analysis revealed that the expression levels of genes related to fatty acid metabolism, cholesterol metabolism, glycolipid catabolism, DNA replication, protein translation, cell division and cell wall formation were significantly downregulated in $M$. bovis BCG treated with $V_{B 1}$. In addition, the metabolomics LC-MS data indicated that most of the amino acids and adenosine diphosphate (ADP) were decreased in M. bovis BCG strain after $V_{B 1}$ treatment.
\end{abstract}

Conclusions: This study provides the molecular and metabolic bases to understand the impacts of $V_{B 1}$ on M.bovis $B C G$.

Keywords: Transcriptomics, Metabolomics, BCG, Vitamin $B_{1}$, Growth inhibition

\section{Background}

Mycobacterium tuberculosis (Mtb), causative agent for Tuberculosis, is the leading infectious cause of death worldwide. The difficulties associated with the treatment and control of tuberculosis are mainly due to the ability of Mtb to persist in a dormant state and maintain viability in the absence of cellular replication. Although the use of anti-TB drugs such as rifampicin (RIF) and isoniazid (INH) has been widely accepted, the treatment outcome may be worsened by the presence of multidrug resistant (MDR) strains of Mtb. Moreover, the appearance of MDR and XDR (extensively drug resistant) strains can reduce the treatment success in TB. Therefore, the discovery of novel anti-Tuberculosis drugs and the implementation of effective Tuberculosis prevention programme have become a major focus of Tuberculosis research.

\footnotetext{
* Correspondence: liusiguo@caas.cn

State Key Laboratory of Veterinary Biotechnology, Harbin Veterinary Research Institute, Chinese Academy of Agricultural Sciences, Harbin, China
}

The application of transcriptomics has been driven by bioinformatic analysis for the identification of key variable genes that upregulated and downregulated in bacterial strains under different conditions. The primary aim of this approach is to decipher how the pathogens regulate their gene expression and host transcriptional machinery. This approach will provide a better understanding of molecular events and help to identify the key genes responsible for the pathogenesis of Mtb under different exposure conditions. For instance, transcriptional studies have been applied in Mtb under nutrient starvation, acidic and oxidative stress conditions [1-3]. Moreover, transcriptional profiling have been carried out on soil bacterium $M$. smegmatis and Mtb following the exposure to low and high levels of hydrogen peroxide and to vitamin $\mathrm{C}(\mathrm{Vc})$, respectively $[4,5]$. In vivo, macrophages with similar host environment have been used to study the host response to infection [5]. Numerous transcriptional studies have been conducted using primary cultures of human and murine macrophages [6-8].

(c) The Author(s). 2019 Open Access This article is distributed under the terms of the Creative Commons Attribution 4.0 International License (http://creativecommons.org/licenses/by/4.0/), which permits unrestricted use, distribution, and reproduction in any medium, provided you give appropriate credit to the original author(s) and the source, provide a link to the Creative Commons license, and indicate if changes were made. The Creative Commons Public Domain Dedication waiver (http://creativecommons.org/publicdomain/zero/1.0/) applies to the data made available in this article, unless otherwise stated. 
Metabolomics has been used to describe the complete set of complicated and interrelated chemical transformations that enable individual cells to replicate and survive. Metabolite represents the final downstream outcome of genome transcription, which contains a mixture of highand low-molecular weight compounds involved in the metabolic reactions during normal cell growth and preservation [9]. Due to the importance of metabolism, numerous studies have been focused on Mtb metabolism, including central carbon metabolism [10], cofactor metabolism [11, 12], sulfur, nitrogen and phosphorus metabolism [13, 14]. More importantly, metabolomic analysis enables us to identify the potential biomarkers for diseases. For instance, the impact of Mtb infection on host metabolism has been studied in several experimental models such as mice and guinea pigs $[15,16]$. Moreover, clinical subjects with distinct metabolite profiles have been used to distinguish uninfected patients from those with active disease and latent infection.

Thiamin (Vitamin $B_{1}$ ), in its active form thiamin diphosphate (ThDP), is an essential cofactor for all organisms [17-19]. Vitamin $B_{1}\left(V_{B 1}\right)$ is involved in energy metabolism and the degradation of sugars and carbon skeleton [19]. $V_{B 1}$ has a multifaceted role in the regulation of gut immunity by maintaining the functions of naive $B$ cells and utilizes the energy released from the citric acid cycle [20]. In addition, $\mathrm{V}_{\mathrm{B} 1}$ participates in the activation of immune system, nerve tissue repair, neuronal communication, brain development, brain function and cell-membrane dynamics [21-23]. Furthermore, $V_{B 1}$ can diminish the concentrations of reactive nitrogen species in cells as a consequence of its antioxidant activity, but has no significant effects on reactive oxygen species [24]. Despite the fact that bacteria, fungi and plants are able to synthesize $V_{B 1}$ de novo, mammals are entirely reliant on a dietary source of $V_{B 1}$. Nevertheless, $V_{B 1}$ deficiency may result in an increased lactic acid production and lead to metabolic and neurological disorders [25].

To date, vitamin $\mathrm{A}\left(\mathrm{V}_{\mathrm{A}}\right), \mathrm{V}_{\mathrm{C}}$ and vitamin $\mathrm{D}\left(\mathrm{V}_{\mathrm{D}}\right)$ supplementation have been used as adjunct to anti-tuberculosis drugs [26-28]. $V_{C}$ is capable of inhibiting the growth of Mtb due to the reduction of ferric to ferrous ions. The ferrous ions may result in the production of reactive oxygen species (i.e. hydrogen peroxide, superoxide and hydroxyl radicals) through Harber-Weiss cycle and Fenton reactions, which give rise to pleiotropic effects associated with certain cellular processes [28], $V_{D}$ itself may not exert anti-TB activity; instead, its metabolite $1,25(\mathrm{OH})_{2} \mathrm{D}_{3}$ $\left(1 \alpha, 25\right.$-dihydroxyvitamin $\left.\mathrm{D}_{3}\right)$ can inhibit the growth of Mtb and regulate the immunity of host cells via phagosome-lysosome fusion [29]. Additionally, $\mathrm{V}_{\mathrm{B} 5}$ can reduce the growth of intracellular Mtb in macrophage in vitro, and confer protection against mycobacterial infection by enhancing the maturity of macrophages and inducing the differentiation of Th1 and Th17 cells in mice infected with Mtb [30]. Our recent study demonstrated that $V_{B 1}, V_{C}$ and $V_{A}$ can decrease the binding affinity between Rv3291c(MtbLrpA) and DNA [31]. In addition, in our data we found that $V_{B 1}$ with a final concentration of $10 \mathrm{mM}$ can inhibit the growth of BCG in vitro. By considering the importance of $V_{B 1}, V_{A}, V_{C}$ and $V_{D}$, we proposed that lacking certain vitamins may play a role in bacterial persistence.

Therefore, in the present study, the transcriptomic and metabolomic analyses were conducted on $M$. bovis BCG after $V_{B 1}$ induction, by using RNA-sequencing and LC-MS platforms, respectively. The results indicated that $V_{B 1}$ exhibited an inhibitory effect on the growth of BCG in vitro. Candidate genes involved in the cell wall formation, energy metabolism and metabolic regulation were differentially expressed in BCG cultures in the absence and/or presence of $V_{B 1}$. Furthermore, the concentrations of amino acids and metabolites such as adenosine diphosphate (ADP), inosine and so on were decreased after $V_{B 1}$ treatment.

\section{Results}

Inhibitory effects of $V_{B 1}$ on BCG growth and its minimum inhibitory concentration

Previous study demonstrated that $\mathrm{V}_{\mathrm{D}}$ can suppress the intracellular growth of $M$. tuberculosis in vitro [32]. In addition, the high dose of $\mathrm{V}_{C}$ was found to sterilize $M$. tuberculosis cultures in vitro [28]. In the present study, $\mathrm{V}_{\mathrm{B} 1}$ was added in certain medium at different final concentration of 1.0, 2.0,4.0,8.0,10 mM, in order to test the effect of $\mathrm{V}_{\mathrm{B} 1}$ on BCG growth. It was observed that 8 $\mathrm{mM} \mathrm{V}_{\mathrm{B} 1}$ has inhibited the growth rate of BCG (Fig. 1). In addition, the minimum inhibitory concentration (MIC) of $\mathrm{V}_{\mathrm{B} 1}$ was detected as $8 \mathrm{mM}$ (data not shown).

\section{Genome expression analysis of BCG following $V_{B 1}$ treatment}

A total of 100 genes (2.5\% of whole genome) were induced, whereas 160 genes (4\% of whole genome) were repressed for more than 2-fold (Additional file 1: Table S3). Fold changes were calculated by the power of 2 for all the studied genes. For both GO and KEGG enrichment analyses, corrected $\mathrm{P}<0.05$ was selected as a threshold to determine the significant enrichment of each gene set. The genes with an adjusted $P$-value of $\leq 0.05$ were identified as differential expression. GO analysis of the transcripts was identified through Bio::SAGE::Comparison tool (https:// metacpan.org/pod/Bio::SAGE::Comparison). The GO enrichment transcriptional analysis revealed that the differentially expressed genes in BCG strain treated with $8 \mathrm{mM}$ of $V_{B 1}$ were significantly enriched in the following functional categories:"cell wall", "cytosol", "response to host immune response", "cellular response to nitrosative 


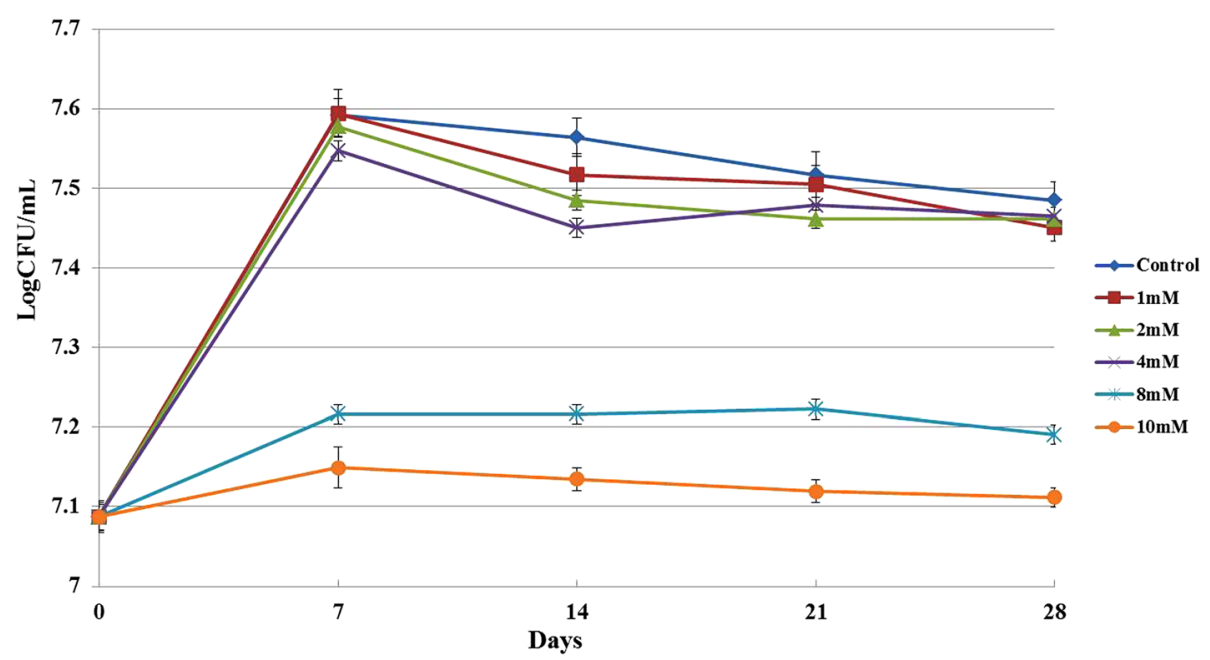

Fig. 1 Effect of $V_{B 1}$ on $B C G$ growth. $B C G$ cultures were inoculated into $7 \mathrm{H} 9$ liquid medium, and treated with different concentrations of $V_{B 1}$ (1.0, 2.0, 4.0, 8.0, $10.0 \mathrm{mM}$ ). $\mathrm{BCG}$ cultures without $\mathrm{V}_{B 1}$ treatment were used as controls. The $\mathrm{OD}_{600 \mathrm{~nm}}$ value was detected every seven days. Each condition was tested in triplicates. $X$-axis represents the time (Unite is day), while Y-axis represents the log of CFU count

stress", "response to hypoxia"(Fig. 2a). On the other hand, KEGG analysis of the transcripts was performed by BLAST against KEGG database. KEGG enrichment analysis indicated that most of the variable genes were associated with the following biological processes: "microbial metabolism in diverse environments", "biosynthesis of antibiotics", "carbon metabolism", "two-component system", "biosynthesis of amino acids", "nitrogen metabolism" and "fatty acid metabolism"(Fig. 2B). The major identified functional groups are discussed below.

\section{NarGHJl operon}

The 4-gene NarGHJI operon, JTY_RSO6200 (narG) to JTY_RSO6215 (narI) were downregulated at different degree and NarG was repressed 2-fold in $\mathrm{V}_{\mathrm{B} 1}$ treated culture (Additional file 2: Table S7). NarGHJI operon encodes for nitrate reductase, an enzyme that reduces nitrate to nitrite during the absence of oxygen, representing the first step of ammonification and denitrification [33]. Nitrogen and nitrogen compounds play an important role in the battle between hosts and pathogens. Nitrate reductase utilizes reactive nitrogen intermediates to promote the growth of Mtb in macrophages. During this process, NarG encoding nitrate reductase may play an essential role. Interestingly, NarG is a conserved protein in mycobacteria, and can be used as an ideal taxonomic marker for sorting different species in mycobacterium [33]. Besides, NarG mutant strains have been used to infect the severe combined immunodeficient mice, which leads to less extensive tissue damage compared wild type strains, indicating that nitrate respiration contributes significantly to the virulence of $M$. bovis BCG [34].

\section{Regulators}

Mtb exhibits an increased pathogenicity due to its ability to adopt a dormant state, which may retain a lifelong risk of latent tuberculosis infection. The regulators play an important role in response to the surrounding environmental conditions, by changing the expression levels of the corresponding genes. In the present study, a total of 20 genes constituting approximately $10 \%$ of all BCG regulators were significantly altered in response to $V_{B 1}$ treatment. It is noticeable that five group of two-component transcription regulators were significantly changed in BCG cells after $\mathrm{V}_{\mathrm{B} 1}$ treatment.

The downregulation of JTY_RS10535 (Rv2034) may regulate the expression of $\operatorname{dos} R$ gene and plays a significant role in lipid metabolism and hypoxic adaptation [35]. In addition, $R v 2034$ is one of the in vivo expressed Mtb antigens (IVE-TB), which is considered as the potential TB vaccine candidate antigen. This observation is based on the expression of $R v 2034$ during the process of inflammatory pulmonary infection and the specificity of cloned T cells for Rv2034 to inhibit Mtb outgrowth from infected monocytes [36, 37]. The downregulated $J T Y_{-} R S 18665$ (Rv3574) is a member of TetR family transcriptional regulators, which is highly conserved in the mycobacteria. This multiple stress responsive transcriptional regulator controls a number of regulons that participate in the lipid degradation and induces the corresponding genes associated with lipid metabolism. Moreover, JTY_RS18665 (Rv3574) positively regulates KstR and potentially acts as the main regulator of lipid metabolism during hypoxia-induced dormancy $[38,39]$.

In the Mtb transcriptional regulatory network, $J T Y \_R S 00450$ (Rv0081) represents an essential regulatory hub and modulates the response to hypoxia in the 
(A)

(5) protein kinase activity (5) protein homodimerization activity(16) protein binding

(11) molecular_function-

(5) magnesium ion binding.

(8) DNA binding

(5) ATP binding

(33) cytosol- $A$

(61)cell wall-

(14) response to hypoxia

(26) response to host immune response

(5) response to copper ion

(4) response to acid

(4) regulation of transcription, DNA-templated

(10) protein homooligomerization

(4) protein autophosphorylation

(7) pathogenesis -

(8) oxidation-reduction process
(4) nitrate assimilation

(4) negative regulation of transcription, DNA-templated

(5) interaction with host

(12) cellular response to nitrosative stress

(4) cell redox homeostasis

(12) biological_process .

(4) Actinobacterium-type cell wall biogenesis

Top 30 of GO Enrichment

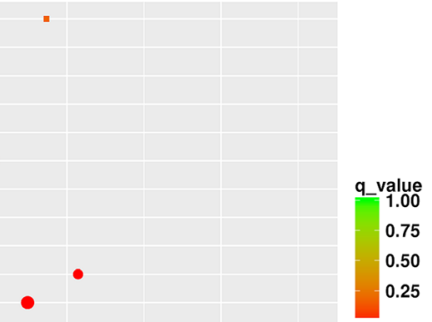

GO_domain

- biological_process

- cellular_component

- molecular_function

Gene_number

- 20

40

60

(B)

Top 30 of Pathway Enrichment

(3) Valine, leucine and isoleucine degradation-

(6) Two-component system

(1) Terpenoid backbone biosynthesis

(1) Sulfur relay system

(3) Sulfur metabolism-

(4) Propanoate molism-

(2) Porphyrin and chlorophyll metabolism

(4) Nitrogen metabolism

(13) Microbial metabolism in diverse environments -

(2) Longevity regulating pathway

(1) Homologous recombination

(4) Glyoxylate and dicarboxylate metabolism-

(1) Glycerolipid metabolism -

(1) Geraniol degradation -

(2) Galactose metabolism

(4) Fatty acid metabolism (2) Fatty acid biosynthesis

(3) Cysteine and methionine metabolism-

(3) Citrate cycle (TCA cycle)(8) Carbon metabolism

(2) Carbon fixation pathways in prokaryotes-

(3) Butanoate metabolism-

(1) Biotin metabolism

(4) Biosynthesis of siderophore group nonribosomal peptides

(12) Biosynthesis of antibiotics-

Biosynthesis of amino acids -

(2) beta-Alanine metabolism

(1) Ascorbate and aldarate metabolism

(2) Amino sugar and nucleotide sugar metabolism

$$
\begin{array}{lrr}
2.5 & 5.0 & 7.5 \\
\text { Rich Factor } & 10.0
\end{array}
$$

Fig. 2 GO enrichment and KEGG pathway analysis of BCG treated with 8 mM V $\mathrm{B}_{\mathrm{B} \text {. }}$ (a) GO enrichment analysis. (b) KEGG pathway analysis. The numbers of genes in Top 30 of GO and Pathway Enrichment are listed on the left side of the figures, respectively

long-term survival of M. tuberculosis [40]. Previous study has reported that the incubation of this protein with whole blood isolated from latently infected individuals may stimulate the activation of IFN- $\gamma$, suggesting the antigenic properties of this protein [41]. In $\mathrm{V}_{\mathrm{B} 1}$-treated culture, JTY_RS00450 (Rv0081) was downregulated by 13-fold (Additional file 2: Table S2).

DosR, a crucial regulator, belongs to two component regulatory system, which enhances dormancy adaptation of M. tuberculosis under low oxygen conditions and is responsible for latent tuberculosis infection. Upon exposure to hypoxia, nitric oxide, carbon monoxide, or ascorbic acid, DosR induces the expression of 48 genes that are referred as DosR regulon, including $\operatorname{dos} R S$, $h s p X$, narK2, tgs1 and so on [42-46]. However, only a few of these regulon have been functionally characterized, while most of them are of unknown function [47]. A recent study has demonstrated the role of DosR 
regulon in metabolic adaptation, which is important for Mtb to shift from an actively respiring to dormancy [48]. Hence, the function of DosR regulon is indispensable for bacterial survival during the dormant state and $J T Y \_R S 16225$ (Rv3133c) was repressed by 5 -fold in $\mathrm{V}_{\mathrm{B} 1}$-treated culture in this study (Additional file 2: Table S2).

When M. tuberculosis is in its dormant state, this pathogen can persist in a hostile environment through many different ways. One of these is the rapid downregulation of ribosome biogenesis to match the decreased translational demand, which requires the coordinate transcriptional regulation of the synthesis of all ribosome elements. CarD is an essential protein that modulates the mycobacterial rRNA transcription. Loss of CarD has been reported to be lethal for mycobacteria in vitro and during infection of mice. Moreover, CarD depletion may increase the susceptibility of $M$. tuberculosis to being killed by starvation, oxidative stress and DNA damage, accompanied by failure to reduce rRNA transcription [49]. In this study, JTY_RS18710 (Rv3583c) was decreased more than 2-fold in $\mathrm{V}_{\mathrm{B} 1}$ supplemented culture (Additional file 2: Table S2).

The metabolic regulator JTY_RS17900 (WhiB3) was up-regulated more than 2.4-fold in $\mathrm{V}_{\mathrm{B} 1}$-treated mycobacterial cells (Additional file 2: Table S2). WhiB3 includes the $4 \mathrm{Fe}-4 \mathrm{~S}$ (iron-sulfur) cluster proteins and serves as a redox sensor and effector molecule, which regulates the redox homeostasis and virulence via interaction with specific host gases (e.g. $\mathrm{O}_{2}$ and NO) [50]. The expression of WhiB3 is drastically increased upon acid stress, while weakly induced upon exposure to oxidants during the growth of Mtb under different environmental pressure conditions [51]. In $\mathrm{V}_{\mathrm{C}}$ and $\mathrm{H}_{2} \mathrm{O}_{2}$-treated mycobacterial cells, the expression of WhiB3 is induced more than 2 -fold. Thus, both $\mathrm{V}_{\mathrm{C}}$ and peroxide can stimulate the expression of the corresponding protein $[4,52,53]$.

Under nitric oxide treatment and macrophage infection, the expression level of transcription regulator $J T Y \_R S 20155$ (WhiB6) is highly upregulated [54]. WhiB6 is able to regulate the expression of ESX-1 during mycobacterial dissemination and granuloma formation in zebrafish embryo model [55]. Through comparative transcriptomic analysis, WhiB6 has been shown to regulate aerobic and anaerobic metabolism, virulence and cell division [54]. In $\mathrm{V}_{\mathrm{B} 1}$-treated cells, JTY_RS20155 (Rv3862c) was upregulated more than 3-fold (Additional file 2: Table S2).

The repressor JTY_RS20120 (Rv3855) belonging to TetR/CamR family transcriptional regulators was upregulated by approximately 2-fold in $\mathrm{V}_{\mathrm{B} 1}$-treated culture (Additional file 2: Table S2). In Mycobacterium genome, $R v 3854 c$ (ethA) and Rv3855 (ethR) can confer to the resistance to antitubercular drug ethionamide (ETH) among patients infected with MDR strains of $M$. tuberculosis. In addition, the ethA-ethR-deficient $M$. bovis BCG mutant displays an increased adherence to mammalian cells and enhanced persistence in vivo [56].

Rv3066 is one of TetR family regulator and represses the transcription of $m m r$ by directly binding to the inverted repeat (IR) of promoter [57], $\mathrm{Mmr}(\mathrm{Rv} 3065)$ is a multidrug efflux pump, which belongs to the SMR (small multidrug resistance) family. Mmr can modulate the resistance to some toxic compounds, including ethidium bromide, acriflavine, safranin O, pyronin Y, tetraphenylphosphonium and thioridazine [58, 59]. Furthermore, $\mathrm{Mmr}$ is able to recognize and eliminate a large range of antimicrobial agents, thus leading to the intrinsic resistance to antimicrobials in Mtb. The results of transcriptomics analysis demonstrated that JTY_RS15890 (Rv3066) was upregulated by 2-fold in $\mathrm{V}_{\mathrm{B} 1}$-treated cells (Additional file 2: Table S2).

\section{DNA replication, translation and repair}

The $M$. tuberculosis genome encodes an $\mathrm{NAD}^{+}$-dependent DNA ligase (ligA) and three diverse ATP-dependent ligase homologs, namely, $\operatorname{lig} B$, $\operatorname{lig} C$, and $\operatorname{lig} D$ [60]. Two of them are repressed in $\mathrm{V}_{\mathrm{B} 1}$-treated $\mathrm{BCG}$ cultured cells, suggesting that the reduced growth rate of BCG was possibly due to the retardation of replication process.

The detected genes were also involved in the process of translation, such as those encoded by $50 \mathrm{~S}$ ribosomal proteins (i.e. $r p m B 1, r p l E, r p l D, r p l C, r p l W$ and $r p l B$ ) were downregulated, leading to a decrease in the demand for mRNA and protein synthesis during the state of dormancy. In addition, JTY_RSO0440 (Rv0079), a member of DosR regulon, is involved in the regulation of translation initiation via the interaction between bacterial ribosomal subunits and its products in order to inhibit the protein synthesis and bacteria growth [61-63]. It was observed that the expression level of Rv0079 was 6-fold lower after $\mathrm{V}_{\mathrm{B} 1}$ treatment (Additional file 2: Table S2).

In addition, high-level expression of chaperone proteins under various stress conditions may prevent the irreversible loss of protein function [64]. GroEL is believed to function as chaperonin cage, which can alter the rate of protein folding [65]. Although the mechanism underlying GroELs-facilitated protein folding is not clearly understood, it has been observed that these GroELs do not demand ATP to promote protein folding [66]. In this study, JTY_RSO2300 (Rv0440) that encodes molecular chaperone GroEL was identified to be upregulated 2-fold in $\mathrm{V}_{\mathrm{B} 1}$-treated samples (Additional file 2: Table S2).

Response to DNA damage is crucial for bacterial survival. The JTY_RS14065 (Rv2720) LexA is a key element of SOS regulatory network involved in the bacterial 
response to DNA damage, which is commonly found among bacteria and displayed a substantial discrepancy in transcriptional regulation [67]. In $\mathrm{V}_{\mathrm{B} 1}$-treated BCG culture, the expression level of lexA was decreased, suggesting that the activation of DNA repair system in BCG is essential for dormancy survival.

\section{Energy metabolism (fatty acid/cholesterol/glycolipid)}

Acquisition and utilization of nutrients within the host cells is one of the main factors contributing to the long-term persistence of Mtb. Certain lipid precursors, such as cholesterol are required for the host cells, which can promote the survival of Mtb and its infection [68]. The results of transcriptomic analysis indicated that the majority of the genes related to cholesterol metabolism were downregulated in $\mathrm{V}_{\mathrm{B} 1}$-treated BCG culture. For example, JTY_RS18520 (fadA5) encoding for acetyl-CoA-acetyltransferase is involved in the catabolism of cholesterol, which provides a carbon source for energy production. In the infectious mouse model, the fadA5 mutant showed an attenuated disease phenotype as compared to the wild-type strain during chronic infection. Therefore, fadA5 is considered crucial to the survival of Mtb in vivo, and can be used as a potential drug target [69]. Additionally, JTY_RS18515 (cyp125), a cholesterol hydroxylase gene, is encoding cytochrome-P450-steroid-C27-monooxygenase, which involved in the cholesterol catabolism of M. bovis BCG, Mtb and other strains [70].

$J T Y \_R S 18475(k s t D)$ encodes 3-oxosteroid-1-dehydrogenase that regulates cholesterol through 4-androstene-3,17-dione/1,4-androstadiene-3,17-dione (AD/ ADD) pathway. Deletion of $k s t D$ gene may suppress Mtb growth due to the inactivation of cholesterol degradation pathway.

$J T Y_{-} R S 16210$ (tg1) encodes diacylglycerol-O-acyltransferase enzyme and is potentially encoding triacylglycerol synthase (TGS). Triacylglycerol (TG) is widely used as an energy source for the intracellular growth of pathogen. It is reported that the accumulation of TG is essential for the metabolism of Mtb [71]. In this study, the expression levels of $R v 3130 c$ ( $\operatorname{tg} 1$ ) were downregulated 14-fold in BCG culture following $\mathrm{V}_{\mathrm{B} 1}$ treatment (Additional file 2: Table S2).

Nitrogen and nitrogen compounds play an important role in the battle between M.tuberculosis and host cells. M.tuberculosis can utilize nitrate as a final electron acceptor under anaerobic conditions to enhance its survival. Certain genes involved in nitrogen assimilation such as JTY_RS01345 (Rv0253), JTY_RS06200 (Rv1161) and JTY_RSO1340 (Rv0252) were repressed more than 2-fold in $\mathrm{V}_{\mathrm{B} 1}$-treated cells (Additional file 2: Table S2). Besides, the expression levels of operon NarGHJI encoding nitrate reductase were also decreased.
Through metabolic adaptation, M. tuberculosis encounters a range of different microenvironments in its host. Glucose is one of the most abundant and essential carbon sources for many pathogenic bacteria such as $M$. tuberculosis. In $M$. tuberculosis, glycolytic pathway is highly conserved and fructose-6-phosphate phosphorylation is the key step in glycolysis process catalyzed by phosphofructokinase (PFK) activity. The genomic analysis predicted that there are two genes, namely, $p f k A$ $(r v 3010 c)$ and $p f k B$ (rv2029c), encoded for putative PFK. Recent studies demonstrated that PFKA of Mtb accounted for the overall PFK activity without functional redundancy of PFKB. Notably, the minor isoenzyme PFKB of $E$. coli is responsible for around $10 \%$ of PFK activity. It is thus possible that Mtb PFKB possesses the ability to phosphorylate sugar-based substrates in addition to fructose-6-phosphate [72]. In $\mathrm{V}_{\mathrm{B} 1}$ treated culture, JTY_RS10510 (rv2029c) was downregulated by approximately 50 -fold (Additional file 2: Table S2).

In overall, the majority of these genes are participated in energy metabolism, including the fatty acid, cholesterol and glycolipid metabolism. It is postulated that pathogens downregulated its metabolic activity to reduce energy consumption and to persist in a prolonged dormant state.

\section{lon-related protein}

The balance of metal ions (e.g. iron, copper, zinc and magnesium) concentrations in the host cell is crucial for the adaptation to the environmental changes during the host responses to pathogen invasion. Bacterial growth is involved in a series of biological actions in terms of storage, transport and the use of metal ions. Recently, copper has been proposed to be used directly as a host defense mechanism, since a high concentration of copper was found in the mycobacterial phagosome [73]. The elevated copper levels are toxic and harmful to the cells through the induction of oxidative stress via Fenton reactions [74]. In addition, high copper levels can induce Fe-S clusters destabilization [75] and replace metal cofactors in proteins. Nevertheless, copper has been shown to act as a metalloenzyme cofactor and is mainly involved in controlling all types of cellular activities [76].

$J T Y \_R S 05125($ csoR $)$ is an essential gene that is necessary for the retention of copper homeostasis in Mtb, while the target deletion of $c s o R$ is able to promote survival of Mtb during the early stages of chronic infection [77]. However, $c s o R$ has been shown to repress the expression of $c s o$ operon in the absence of copper [78]. In the present study, cso operon (csoR-Rv0968-ctpV-Rv0970) was up-regulated by approximately 2-fold in $\mathrm{V}_{\mathrm{B} 1}$-treated BCG cultured cells (Additional file 2: Table S2). Moreover, $c t p V$ (JTY_RS05135) potentially functions as a copper exporter and is essential for copper detoxification in Mtb. In animal 
models, $c t p V$ deletion mutant exerts a potent strong effect on host immune response in Mtb [79]. Overall, these findings suggest that $M$. bovis BCG is able to adapt to $\mathrm{V}_{\mathrm{B} 1}$ treatment conditions, by regulating the copper concentrations, control the exports of copper and retain a safe intracellular environment for Mtb to maintain its dormant phase.

\section{Transport}

$A B C$ transporters are crucial for survival of Mtb, with regard to nutrients uptake and toxicants efflux. In Mtb genome, approximately $2.5 \%$ genes encode the $\mathrm{ABC}$ transporter proteins, including peptide transporters, macrolide transporters, amino acid transporters, carbohydrate transporters, iron transporters, anion transporters and so on [80]. In particular, there are two peptide permease operons $d p p$ (rv366c-rv3663c) and opp (rv1283c-rv1280c) in the genomic sequence of M. tuberculosis H37Rv [81]. Both contain two nucleotide-binding subunits and integral membrane proteins, and one substrate-binding polypeptide [82]. The rv3665c-rv3662c encodes for the oligopeptide transporter of $M$. tuberculosis, basing on the fact that an rv3665c-rv3662c knockout mutant is resistant to bialaphos [83]. Microarray expression profiling has clearly indicated that the $r v 3665 c-r v 3663 c$ locus regulates at least some genes which are induced during nutrient deprivation and hypoxia [81]. In the present study, our expression results indicated that $d p p A-d p p B-d p p C-d p p D(R v 3666 c-R v 3665 c-$ $R v 3664 c-R v 3663 c)$ genes were all downregulated.

Mtb UspABC transporter, one of four Mtb ABC transporters, has been shown to be essential for the growth of M. tuberculosis in vitro [84]. UspABC transporter may have a key function in the assimilation of amino sugars that enables Mtb to optimize the use of limiting nutrients during intracellular infection [85]. This observation supports the possible role of UspABC transporter in the recycling ingredient of cell-wall peptidoglycan [85]. Furthermore, our data demonstrated that the expression levels of usp $A B C$ operon were downregulated more than 2-fold in BCG culture supplemented with $\mathrm{V}_{\mathrm{B} 1}$ (Additional file 2: Table S2).

\section{Cell wall formation}

The cell walls of Mtb have a high lipid content, which are composed predominantly of mycolic acids. Cell walls may play an important role in Mtb pathogenesis through the control of its own cellular processes, including neutralization of free radicals, alterations in membrane permeability and modulation of host immune response [86]. Mycolic acids are able to increase host survival rates and reverse antibiotic resistance, due to low permeability of cell walls. Therefore, identification of the major enzymes involved in mycolic acid biosynthesis may lead to the development of novel drug targets for TB treatment. In Mtb, there are six $a c c D$ genes encoding for acyl-CoA carboxylases. Notably, JTY_RS05160 (rv0974c) or known as accD2, is believed to take part in mycolic aicd biosynthesis. Cell wall-bound mycolic acids were absent in $a c c D 2$ and $a c c D 3$ mutants, suggesting that these mutants are indeed deficient for mycolic acid synthesis [87]. The transcriptomic analysis demonstrated that $r v 0974 c$ was almost 4-fold lower when treated with $\mathrm{V}_{\mathrm{B} 1}$ (Additional file 2: Table S2).

JTY_RS10525 $(R v 2032 c)$ or acg gene, encoding the $\mathrm{NAD}(\mathrm{P}) \mathrm{H}$ nitroreductase, was downregulated about 30-fold in $\mathrm{V}_{\mathrm{B} 1}$ treated BCG culture (Additional file 2: Table S2). Deletion of acg produced a mutant that is attenuated in both macrophage and murine model infections. However, acg deletion did not come to terms with the viability of the mutant in vitro and in vivo, under oxidative and nitrosative stresses. Moreover, the acg mutants are more sensitive to antibiotic drugs (e.g. nitrofurantoin and nitrofuran) than the WT strain. Thereby, $a c g$ is a key virulence factor for Mtb, which enhances the growth and survival of Mtb in macrophages and mice [88].

\section{PE and PPE families proteins}

PE and PPE are glycine-rich proteins that constitute approximately $10 \%$ of Mtb proteome. However, the function of these glycine-rich proteins is unknown [89]. Recent studies have proposed that these two protein families may contribute to the bacterial persistence in granulomas, the bacterial survival in macrophages and the antigenic change [90, 91]. During the infection process, phagocytes can kill intracellular microorganisms via the inhibition of phagosome acidification. Further, this prevents the fusion between lysosome and phagosome [92]. It has been reported that a strain lacking $J T Y \_R S 09290(R v 1787)$ is attenuated in vivo and does not inhibit the phagosome-lysosome fusion and the acidification of vacuole, suggesting that this protein may be involved in the development of bacterial intracellular environment and the formation of phagosome [93]. In $\mathrm{V}_{\mathrm{B} 1}$-treated culture, the expression levels of $R v 1787$ were upregulated by approximately 2 -fold (Additional file 2 : Table S2).

In addition, it has been reported that JTY_RS17945 ( $R v 3425)$ is encoded by an open reading frame located in the RD11 region of Mtb genome and this protein is expressed during the exponential growth in vitro [94]. Rv3425 exhibited both IgG1 antibody response and Th1/ Th2 immune response following immunization in mice, supporting that this protein is involved in the production of a potent cellular and humoral immune response. Moreover, vaccines containing Ag85B and Rv3425 antigens promote the effects of immunity and confer a 
protection against Mtb infection in C57BL/6 mice [95]. Therefore, Rv3425 may be a promising vaccine candidate for TB treatment. In the present study, $\mathrm{V}_{\mathrm{B} 1}$ treatment induced a 3-fold increase in Rv3425 expression levels in BCG culture as compared to the control sample (Additional file 2: Table S2).

$J T Y \_R S 10910(R v 2108)$ can be used for the rapid detection and identification of mycobacteria complex containing $M$. africanum, $M$. bovis and $M$. bovis BCG strain, due to its high specificity towards Mtb complex [96]. In a previous study, the recombinant p27-PPE36 (Rv2108) protein is immunologically active and reacts with antibodies in the sera of TB patients, as detected by ELISA assay [97]. It is worthwhile to note that the presence of IgA and absence of IgG antibody responses can be used as the specific diagnosis markers for Mtb [98]. The current transcriptomic data indicated that the expression levels of PPE36 were upregulated more than 3-fold in $\mathrm{V}_{\mathrm{B} 1}$-treated cells (Additional file 2: Table S2).

\section{Hypothetical protein}

The transcriptomic analysis indicated that the expression levels of the 260 genes were altered in the bacterial cells following $\mathrm{V}_{\mathrm{B} 1}$ treatment. Among these genes, 51 (19\%) were encoded for hypothetical proteins. The functions of several hypothetical proteins have been reported, but most of them are of unknown function. For example, the conserved hypothetical genes JTY_RSO9425 (Rv1813c) and the co-transcribed JTY_RS09420 (Rv1812c) are encoded for dehydrogenase. $R v 1813 \mathrm{c}$ is predicted to be related with $\mathrm{Mtb}$ virulence in vivo [99]. In this study, both genes were downregulated at a factor of higher than 9-fold and 2-fold, respectively. Moreover, JTY_RS10515 (Rv2030c), JTY_RS16955 (Rv3269), JTY_RS00440 (Rv0079c), JTY_RS09435 (Rv1815) and JTY_RS13660 (Rv2627c) were downregulated more than 3-fold. In contrast to those genes, JTY_RS12370 (Rv2390c), $J T Y_{-} R S 00960$ (Rv0179c), JTY_RS08085 (Rv1535), JTY RS13125 (Rv2525c) and JTY_RS09350 (Rv1799) were upregulated more than 2-fold (Additional file 2: Table S2).

\section{Universal stress protein}

There are 10 universal stress proteins (ups) in M. tuberculosis, most of the function are unknown. Recently, proteomic and transcriptomic analyses have revealed that a number of $u s p$ genes are significantly upregulated under nitric oxide, carbon monoxide and hypoxia conditions, as well as during $M$. tuberculosis infection of macrophage cell lines [100]. It is worth to mention that the expression levels of 10 universal stress proteins such as JTY_RS10505 (Rv2028c), JTY_RS16230 (Rv3134c), JTY_RS13645 (Rv2624c), JTY_RS13640 (Rv2623c), JTY_RS10325 (Rv1996), JTY_RS10375 (Rv2005c), $J T Y \_R S 12040 \quad(R v 2319 c), \quad J T Y_{-} R S 08515$ (Rv1636c), JTY_RS10495 (Rv2026c) and JTY_RS05465 (Rv1028c) were repressed at different magnitudes. Among these stress proteins, $R v 2028 c, R v 1996$ and $R v 2005 c$ that belong to $M$. tuberculosis DosR regulon were repressed at 36,7 and 2 folds, respectively, among the $\mathrm{V}_{\mathrm{B} 1}$-treated BCG culture (Additional file 2: Table S2).

RT-qPCR verification for the expression of selected genes A total of 20 genes were selected for qRT-PCR examination in order to confirm the obtained transcriptomic data (Fig. 3). The primers used in the qRT-PCR assay are listed as the supplementary materials (Additional file 3: Table S1). The alteration in the levels of expression corresponded to the results of sequencing.

As illustrated in Fig. 3, the genes JTY_RS10385 (Rv2007c), JTY_RS10520 (Rv2031c), JTY_RS16215 (Rv3131), JTY_RS16230 (Rv3134c), JTY_RS16225 (Rv3133c), JTY_RS05530 (Rv1039c), JTY_RS20045 (Rv3841), JTY_RS16220 (Rv3132c), JTY_RS00455 (Rv0082), JTY_RS10510 (Rv2029c) encoding ferredoxin, alpha-crystallin, $\mathrm{NAD}(\mathrm{P}) \mathrm{H}$ nitroreductase, universal stress protein, transcriptional regulator, PPE family protein, ferritin $\mathrm{BfrB}$, histidine kinase, oxidoreductase and phosphofructokinase were downregulated at 32, 46, 13, $11,15,4,6,7,21,9$ folds, respectively. On the contrary, the genes JTY_RS12600 (Rv2428), JTY_RSO7460 (Rv1405c), JTY_RS15805 (Rv3049c), JTY_RS20155 (Rv3862c), JTY_RS02300 (Rv0440), JTY_RS10910 (Rv2108), JTY_RS01000 (Rv0186A), JTY_RS05235 (Rv0986), JTY_RS18025 (Rv3445c), JTY_RS00695 $(R v 0129 c)$ encoding alkyl hydroperoxide reductase subunit $\mathrm{C}$, methyltransferase, $\mathrm{NAD}(\mathrm{P}) / \mathrm{FAD}$-dependent oxidoreductase, transcriptional regulator, molecular chaperone GroEL, PPE family protein, metallothionein, ABC transporter ATP-binding protein, ESAT-6 like protein EsxU and diacylglycerol acyltransferase were upregulated at 25, 13, 7, 6, 11, 4, 9, 5, 6 and 3 folds, respectively (Fig. 3 ).

\section{LC-MS analysis of amino acids and metabolites}

By considering that most of the amino acid metabolic pathways were altered, we aimed to investigate the effects of individual amino acid levels in the $V_{B 1}$-treated and wild strain BCG cultures. The results of LC-MS demonstrated that the concentrations of most amino acids, except for methionine, were higher than 1.0-fold in the $\mathrm{V}_{\mathrm{B} 1}$-treated group as compared to the untreated group (Additional file 4: Table S4).

In addition to amino acids, the metabolites were also detected by LC-MS. Each condition has 6 samples except for 1 sample in control group was ommited because the problem of samples. The heatmap analysis was shown in Fig. 4. Of these, four metabolites, namely, 5-S-methyl-5-thioadenosine, PE (18:1(9Z)/0:0), S-adenosylhomocysteine and LysoPE (0:0/ 18:2(9Z,12Z)) were upregulated at least 2-fold, whereas the 

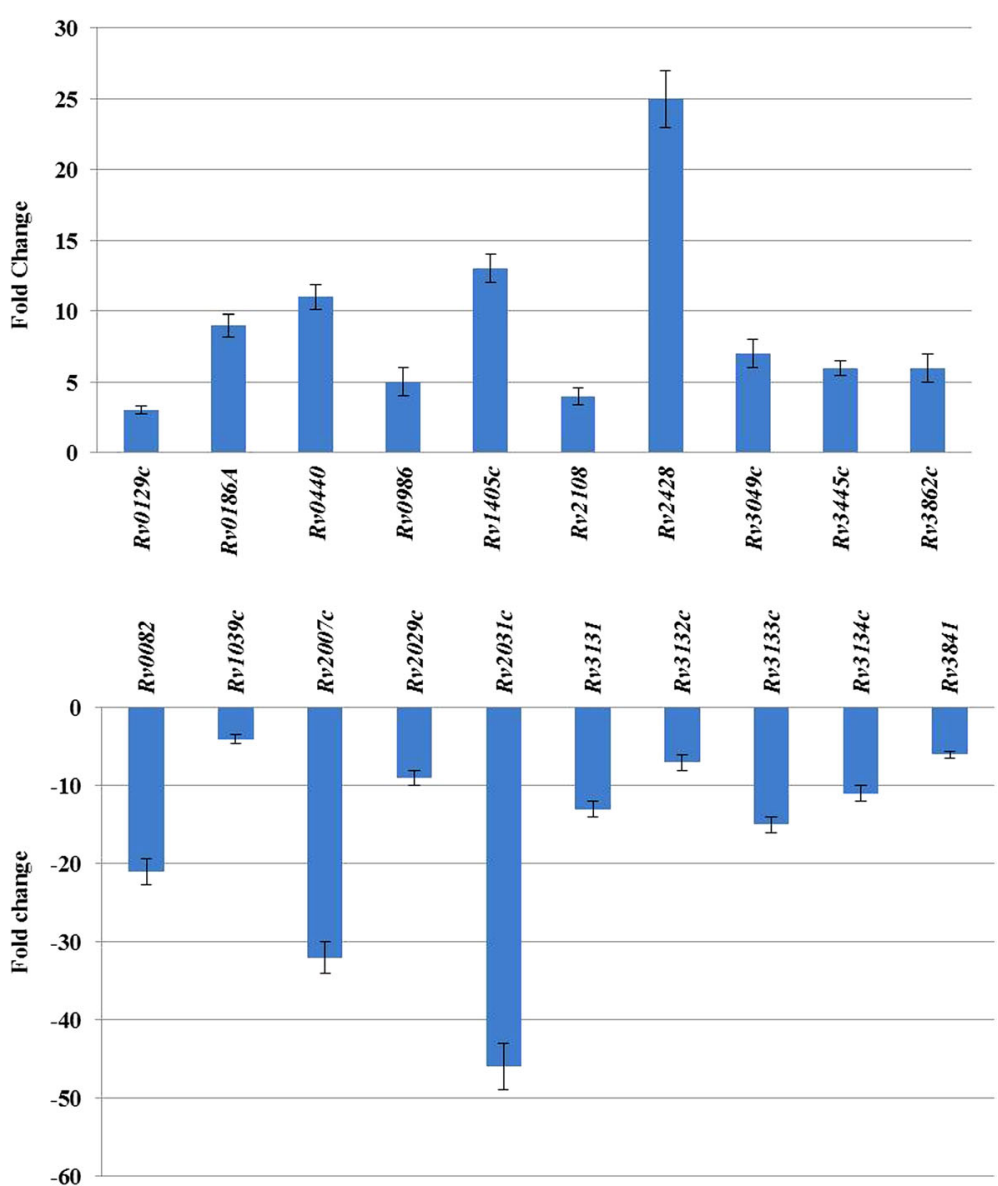

Fig. 3 The relative expression of selected genes. The relative expression levels of selected genes in the presence and absence of $8 \mathrm{mM} V_{B 1}$ by qRT-PCR analysis. Standard deviations (calculated for three biological replicates) are indicated. $X$-axis represents the identities of tested genes; $Y$-axis represents the fold-changes of tested genes in both $V_{B 1}$ treatment and control groups. $\mathbf{a}$ The fold-changes of upregulated genes following $V_{B 1}$ treatment. The genes listed on the X-axis are JTY_RS00695 (Rv0129C), JTY_RS01000 (Rv0186A), JTY_RS02300 (Rv0440), JTY_RS05235 (Rv0986), JTY_RS07460 (RV1405C), JT_RS10910 (Rv2108), JTY_RS12600 (Rv2428), JTY_RS15805 (Rv3049C), JTY_RS18025 (Rv3445C) and JTY_RS20155 (Rv3862C). b The fold-changes of downregulated genes following $V_{B 1}$ treatment. The genes listed on the $X$-axis are JTY_RS00455 (Rv0082), JTY_RS05530 (Rv1039C), JTYRS10385 (Rv2007C), JTYRS10510 (Rv2029C), JTY_RS10520 (Rv2031C), JTY_RS16215 (Rv3131), JTY_RS16220 (Rv3132C), JTY_RS16225 (Rv3133C), JTY_RS16230 (Rv3134C) and JTY_RS20045 (Rv3841)

remaining metabolites including L-tryptophan, inosine, geranylgeranyl PP, adenosine 5-phosphate disodium, 4-nonylphenol and ADP were downregulated by 2-fold (Additional file 5: Table S5).

\section{The associated KEGG pathway for both transcriptomics and metabolomics data}

For the analysis of both transcriptomics and metabolomics data, we explored the KEGG pathway involved in the primary and secondary metabolism of $M$. bovis BCG after $V_{\mathrm{B} 1}$ induction. Differentially expressed genes and metabolites mainly participated in 9 KEGG pathways, including nitrogen metabolism, purine metabolism, methane metabolism, cysteine and methionine metabolism, secondary metabolites biosynthesis, terpenoid backbone biosynthesis, oxidative phosphorylation, photosynthesis and metabolic pathways. The metabolite compounds such as S-adenosylhomocysteine, geranylgeranyl PP, inosine and ADP fluctuated in BCG culture after treated with $\mathrm{V}_{\mathrm{B} 1}$. Moreover, the number of expressed genes involved in metabolic pathways, biosynthesis of secondary metabolites, nitrogen metabolism, purine metabolism, methane metabolism, oxidative phosphorylation and terpenoid backbone biosynthesis were 572, 295, 21, 60, 24, 43 and 27, respectively. All the corresponding genes were downregulated, and the concentrations of ADP, inosine and geranylgeranyl PP were also decreased (Additional file 6: Table S6).

Nitrogen is a basic biomolecule for amino acids, nucleotides, cell wall components and cofactors. Nitrogen metabolism plays an essential role in the life cycle of $M$. tuberculosis. In this study, the 21 genes participating in 


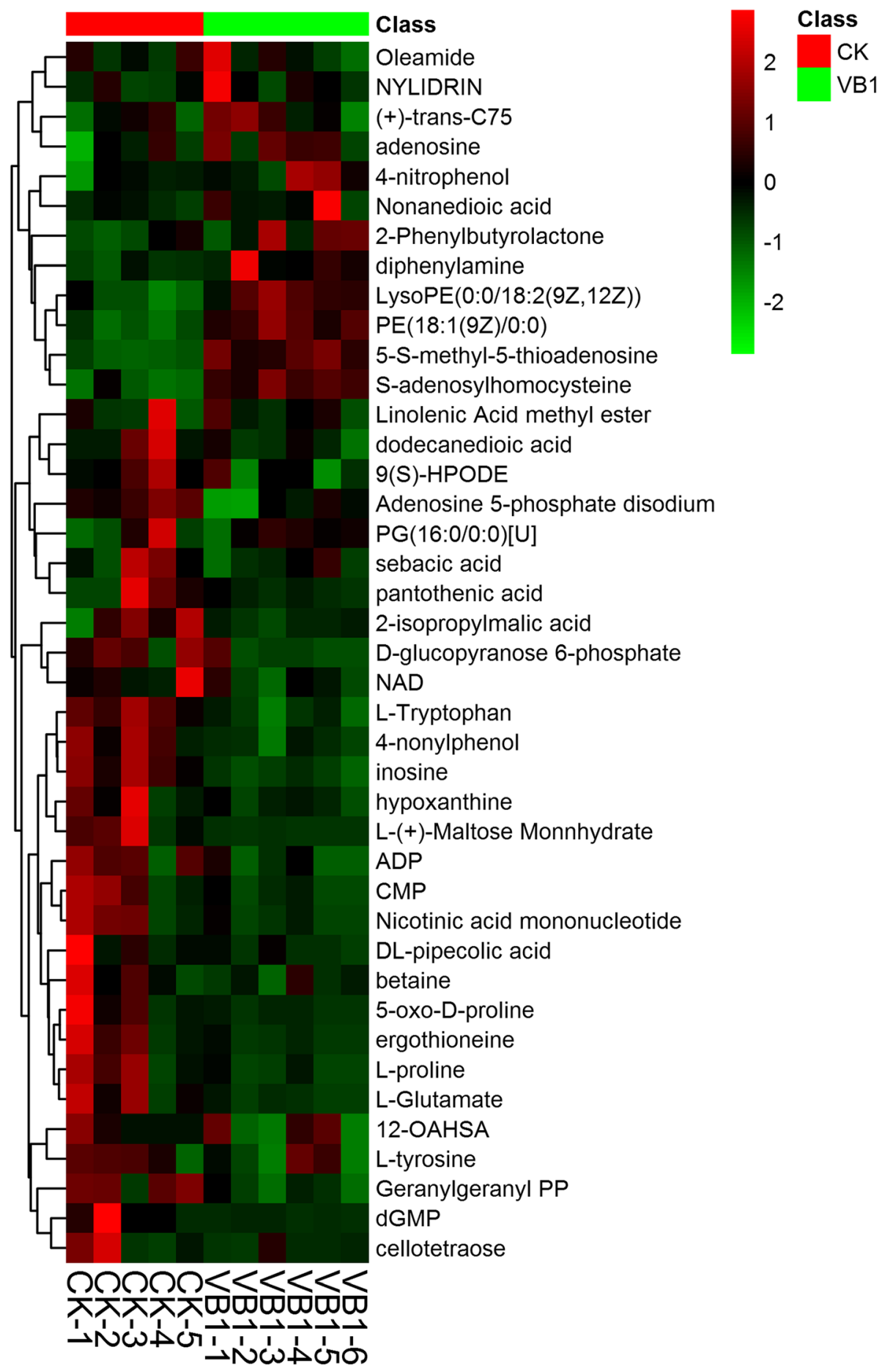

Fig. 4 The heatmap analysis of different metabolites in $V_{B 1}$ treatment and control groups. The red and blue colors indicate metabolites with increased and decreased levels, respectively. The rows represent control samples (CK-1, CK-2, CK-3, CK-4 and CK-5) and experimental samples treated with $V_{B 1}$ $\left(V_{B 1}-1, V_{B 1}-2, V_{B 1}-3, V_{B 1}-4, V_{B 1}-5\right.$ and $\left.V_{B 1}-6\right)$. The identities of metabolites are listed on the right side of the heatmap

nitrogen metabolism were downregulated and the concentration of ADP was decreased in $\mathrm{V}_{\mathrm{B} 1}$-treated culture.

Despite their fundamental importance in forming the building blocks for DNA and RNA, purine metabolites may supply the cells with energy and cofactors to promote cell survival and multiplication [101]. The 60 genes involving in purine metabolism were downregulated at different magnitudes in the $\mathrm{V}_{\mathrm{B} 1}$-treated culture. 
Similarly, the concentrations of ADP and inosine metabolites were reduced.

\section{Discussion}

Vitamin B consists of eight well-recognized members with high water solubility, which is involved in various metabolic pathways and host immunization. $V_{\mathrm{B} 1}$ is a pivotal cofactor for all living microorganisms and exerts a significant function in the activation of immunization. The administration of $V_{B 1}$ as a dietary supplement can reduce the incidence of many types of cancer [102]. In addition, $\mathrm{V}_{\mathrm{B} 1}$ can be used to treat Parkinson's disease via multiple mechanisms of action, including oxidative stress, inflammation, protein expression and cellular metabolism. The therapeutic applications of $V_{B 1}$ have extended to the prevention of immune HIV-associated complications. $\mathrm{V}_{\mathrm{B} 1}$ exerts beneficial effects in HIV patients through the protein expression of vascular endothelial growth factor and matrix metalloproteinase [103, 104]. In the present study, the physiological outcome of $\mathrm{V}_{\mathrm{B} 1}$ treatment in $M$. bovis BCG was examined by both transcriptomic and metabolomic analyses. The findings indicated that $\mathrm{V}_{\mathrm{B} 1}$ treatment could alter various cellular processes involved in the bacterial cell growth. Firstly, $V_{B 1}$ reduces lipid degradation and results in low energy supply, via the downregulation of genes involved in energy metabolism. Secondly, the genes related to cell wall formation, cell division and replication were downregulated, supporting that $\mathrm{V}_{\mathrm{B} 1}$ treatment reduces the growth of BCG. Thirdly, the expression levels of the genes encoding ribosomal synthesis were decreased in BCG cells treated with $V_{B 1}$. These results demonstrated that $V_{B 1}$ treatment may influence the protein synthesis apparatus and reduce protein synthesis, leading to slow bacterial growth. Furthermore, the expression of regulators modulating various cellular processes (e.g. lipid metabolism, lipid degradation, transport and stress response) were altered in BCG culture following $V_{B 1}$ treatment. These data suggests that bacteria can adapt to environmental stimuli via many different regulators by using distinct mechanisms of growth inhibition. Lastly, it is important to note that NarGHJI operon were repressed in BCG treated with $\mathrm{V}_{\mathrm{B} 1}$, indicating that the process of nitrogen assimilation considerably slows down as a consequence of reduced energy sources.

LC-MS based metabolomic analysis revealed that the concentrations of amino acids (AA), except for methionine, were lower in the $\mathrm{V}_{\mathrm{B} 1}$-treated culture than in the untreated culture. In fact, AA are used to support the physiological functions of pathogen, and the variation in AA availability significantly affects the expression of virulence factor and the growth of pathogen [105]. For instance, aspartate is a primary nitrogen source that enhances the virulence of $M$. tuberculosis during colonization of its host [106, 107]. Asparagine is another important nitrogen source for pathogen, which can be captured and digested by AnsP2 and AnsA. Digestion of asparagine may cause pathogens to resist the host immune defense and improve their survival rates in the host [108]. Moreover, alanine can be broken down to pyruvate and ammonium by alanine dehydrogenase, and has been used as an unique nitrogen source for the growth of $M$. tuberculosis, M. avium and M. smegmatis [109]. Both alanine and serine can prevent the growth of BCG strains in vitro by inhibiting glutamine synthetase activity. This enzyme plays an important role in bacterial nitrogen metabolism, metabolizing nitrogen through aminate glutamate in an ATP-dependent reaction [110]. Furthermore, when glycine, asparagine and aspartate are used as the nitrogen source, $M$. bovis BCG can grow rapidly in Sauton medium [111]. More importantly, AA acts as the basic substrate for the synthesis of protein and other regulatory molecules such as nitric oxide, polyamines, and creatin. Besides, AA can regulate MAPK signaling pathways in controlling energy metabolism [112]. Recent studies have shown that AA plays an important role in the coordination of host innate immunity. For example, leucine and glutaminere are crucial in mediating $\mathrm{T}$ cell functions, including the activation and differentiation of Th1 and Th17 cells [113-115].

The combination of transcriptomics and metabolomics data indicated that a large number of annotated genes $(n=572)$ were involved in metabolic pathways, and the corresponding metabolites were identified as ADP, $\mathrm{S}$-adenosylhomocysteine, inosine and geranylgeranyl PP. Next, a total of 295 genes were associated with secondary metabolite biosynthetic pathways, linking to the reduced metabolite levels of ADP and geranylgeranyl PP. Despite the aforementioned pathways, the genes and metabolites involved in nitrogen and purine metabolisms were downregulated. Notably, ATP which is essential for energy production and cofactors function was found to be downregulated by approximately 3.5 -fold. Besides, purine and pyrimidine nucleotides are used to create the DNA and RNA. Purine nucleotides such as ATP is vital for cellular energy supply, while guanosine triphosphate (GTP) and cyclic AMP (cAMP) are the essential signaling molecules [116]. Additionally, purines can be integrated into more complex biomolecules and act as cofactors such as nicotinamide adenine dinucleotide (NAD) and coenzyme A [101]. In this study, inosine was downregulated at least 2-fold in $\mathrm{V}_{\mathrm{B} 1}$-treated BCG culture. Inosine is made up of deaminizing adenosine and can be released extracellularly under inflammatory conditions $[117,118]$. Inosine has been reported to exert nutritional and neuroprotective functions in nerve cells, and stimulates mast cell degranulation by activating adenosine A3 receptor [119]. Moreover, inosine exhibits 
anti-inflammatory activity by inhibiting the release of inflammatory cytokine from activated T cells and promoting the formation of IL-10. Clinical trials have proposed that inosine may be a promising drug target for patients suffering from multiple sclerosis [120].

All in all, the changement of metabolites following $V_{B 1}$ induction suggests a downregulation of gene expression and metabolic pathways in energy metabolism. In addition, abnormal expression of nitrogen metabolism genes and lower concentration of ADP could possibly lead to the slower growth rate of BCG after being treated with $V_{\mathrm{B} 1}$.

\section{Conclusions}

Overall, the findings of this study revealed that $V_{B 1}$ treatment can inhibit the growth of $M$. bovis BCG, by modulating the cellular processes such as replication, transcription, translation, transport and energy metabolism. More importantly, the expression levels of certain antigens were altered in BCG cells following $V_{B 1}$ treatment. These results suggest that $V_{B 1}$ can affect $B C G$ growth by targeting its cellular processes and confer a protection against Tuberculosis by promoting host immunity and stimulating antigen production. Furthermore, metabolomic analysis indicated that most of the amino acid biosynthetic pathways were altered. To the best of our knowledge, the present study is the first to investigate the effects of $\mathrm{V}_{\mathrm{B} 1} M$. bovis $\mathrm{BCG}$, and provides the molecular and metabolic bases to further understand the impacts of $\mathrm{V}_{\mathrm{B} 1}$ on M.bovis BCG.

\section{Methods}

Strains, culture conditions and MIC (minimum inhibitory concentration) of $\mathrm{V}_{\mathrm{B} 1}$

Mycobacterium bovis BCG str. Tokyo 172 strain was grown in Middlebrook 7H9 medium Becton Dickinson supplemented with $0.05 \%$ Tween-80 (V/V), 10\% ADC (Albumin-Dextrose-Catalase, BD) and 0.2\% (V/V) glycerol. When $\mathrm{OD}_{600 \mathrm{~nm}}$ value reached exponential phase, $\mathrm{V}_{\mathrm{B} 1}$ with final concentration of 1.0, 2.0, 4.0, 8.0, $10 \mathrm{mM}$ were added and incubated at $37^{\circ} \mathrm{C}$ for 4 weeks under continuous shaking (100 rpm). At days 7, 14, 21 and 28, $100 \mu \mathrm{L}$ of fresh BCG was spread on the appropriate plates, and then incubated at $37^{\circ} \mathrm{C}$ for 4 weeks. After incubation, the number of colonies was count to determine the effect of $V_{B 1}$ on BCG growth. The experiments were performed in triplicate. For transcriptomics and LC-MS analysis, when OD600nm value reached $0.3, V_{B 1}$ at the final concentration of $8.0 \mathrm{mM}$ for the test group were added and incubated at $37^{\circ} \mathrm{C}$ for $48 \mathrm{~h}$. There are 3 and 6 biological samples respectively in transcriptomics and LC-MS experiments. The procedure of MIC determination is as following: BCG was cultured at $37^{\circ} \mathrm{C}$ for about 10 to 15 days until an optical density (OD) of an
$0.5 \mathrm{McFarland}$ standard $\left(1 \times 10^{7} \mathrm{CFU} / \mathrm{mL}\right)$ reached. Then the suspension was diluted 100 fold to obtain a standard inoculum with $10^{5} \mathrm{CFU} / \mathrm{mL}$. $100 \mu \mathrm{L}$ of standard inoculum was inoculated onto $7 \mathrm{H} 10$ plates containing $\mathrm{V}_{\mathrm{B} 1}$ with final concentration of $0,0.125,0.25,0.5,1.0,2.0$, 4.0, 8.0, $10.0 \mathrm{mM}$ at $37^{\circ} \mathrm{C}$ for 21 days. Then the colony number were counted and the MIC value was confirmed.

\section{RNA extraction and purification}

$M$. bovis BCG was cultured with 7H9 liquid medium in the presence and/or absence of $8 \mathrm{mM} \mathrm{V}_{\mathrm{B} 1}$. At time point $(48 \mathrm{~h})$, bacterial cells (control and $\mathrm{V}_{\mathrm{B} 1}$-treated) were collected and centrifuged. RNA isolation was carried out as described previously [31]. In brief, BCG pellets were lysed and homogenized by high-speed agitation in a bead mill with the presence of glass beads and lysis buffer to lyse the cells and release the RNA. Then total RNA was extracted using RNeasy Mini Kit (Qiagen) following the instructions provided by the manufacturer with one on-column DNase I treatment (Qiagen) at $37^{\circ} \mathrm{C}$ for 30 min in order to remove any contaminating genomic DNA. DNase I was removed with RNeasy mini kit according to the clean-up procedure. All samples were analyzed by using polymerase chain reaction (PCR) with primers SN80f and SN80r (Additional file 3: Table S3), in order to confirm the absence of genomic DNA contamination. The purity of RNA samples was evaluated based on RIN value by using Agilent Bioanalyzer 2100 (Agilent technologies, Santa Clara, CA, US). The concentration of RNA samples was determined by NanoDrop ND-2000. The RNA samples with optimal quantity and purity were selected for next generation RNA-sequencing after cDNA synthesis.

\section{Library construction and data analysis}

The strand-specific library was constructed using TruSeq ${ }^{\circ}$ Stranded Total RNA Sample Preparation kit (Illumina, USA). The ribosomal RNA was removed and the RNA fragments were cleaved, while the first and second strand cDNA were synthesized. A single 'A' nucleotide was added to the $3^{\prime}$ ends of the blunt DNA fragments with repaired ends, and subsequently connected with adapters. The purified libraries were quantified using Qubit $^{\circ}$ 2.0 Fluorometer (Life Technologies, USA) and validated by Agilent 2100 bioanalyzer (Agilent Technologies, USA), in order to measure the concentration and confirm the insert size. The cluster was generated by cBot and RNA sequencing was performed using a $150 \mathrm{bp}$ pair-end strategy with the Illumina Hiseq X10 platform (Illumina, USA) to generate 3 billion bases per sample. Thereafter, raw data was acquired, followed by pretreatment using Septk1. The read length was $>90 \mathrm{nt}$. The number of average clean reads, clean reads ratio and mapping ratio for WT and $\mathrm{V}_{\mathrm{B} 1}$-treated samples were 
3.3G, 97.1 and 99.6\%, and 3.2G, 97.14 and 99.4\%, respectively. We deposited the raw data to GEO repository under accession number GSE114949.

The raw sequencing data were filtered to remove rRNA reads, sequencing adapters, short-fragment reads and other low-quality reads. The cleaned paired-end reads were mapped to M.bovis BCG reference genome with accession number AP010918 by using Tophat v2.0.9 with two mismatches [121]. After the completion of genome mapping, Cufflinks v2.1.1 [122] was run with a reference annotation, in order to generate FPKM (Fragments Per Kilobase of exon model per Million mapped reads) values for known gene models. Cuffdiff analysis was performed to identify the differentially expressed transcripts and genes [118]. False discovery rate (FDR) was used to determine the threshold of $P$-value in multiple tests, on the basis of FDR $\leq 0.05$ and fold-change $\geq 2[123,124]$. Furthermore, the homology of genes in $M$. bovis BCG was compared with $M$. tuberculosis H37Rv genome, by using BLAST analysis (https://blast.ncbi.nlm.nih.gov/Blast.cgi; Additional file 7: Table S2).

\section{CDNA synthesis and qRT-PCR}

cDNA was synthesized using SuperScript III First-Strand Synthesis kit according to the manufacturer's instructions. Quantitative real-time PCR (qRT-PCR) was performed with $\mathrm{iQ}^{\mathrm{m}}$ SYBR Green Supermix (Bio-Rad) by using the LightCycler 480 II (Roche) RT-PCR System. The PCR conditions were as follows: initial denaturation at $95^{\circ} \mathrm{C}$ for $3 \mathrm{~min}$, followed by 40 cycles of denaturation at $95^{\circ} \mathrm{C}$ for $10 \mathrm{~s}$, annealing at $55^{\circ} \mathrm{C}$ for $30 \mathrm{~s}$ and extension at $72{ }^{\circ} \mathrm{C}$ for $10 \mathrm{~s}$. After completion of the 40th cycle, a final cycle of $50{ }^{\circ} \mathrm{C}$ was conducted for $3 \mathrm{~min}$. The reactions were carried out with 50-fold diluted cDNA and 12.5 $\mu \mathrm{L}$ SYBR Green supermix. All reactions were carried out in triplicate, including the cDNA-free template and RT-free control. The Rv2703 gene encoding RNA polymerase sigma A factor (sigA) was selected as a housekeeping gene for normalization of target gene expression levels. PCR reaction efficiency was calculated by evaluating the slope of a standard curve. The curve was created by linear regression of the resulting $\mathrm{C}_{\mathrm{q}}$ values, with a 10 -fold serial dilution of DNA. The $2^{\Delta \Delta \mathrm{Cq}}$ method was used to calculate the relative expression levels of target genes.

\section{LC-MS based metabolomic analysis}

The BCG strains cultured with 7H9 medium in the absence and/or presence of $V_{B 1}$ were collected after $48 \mathrm{~h}$ incubation at $37^{\circ} \mathrm{C}$. In the collected $60 \mathrm{mg}$ pellets, added $500 \mu \mathrm{L}$ of methanol (pre-cooled at $-20^{\circ} \mathrm{C}$ ) and $500 \mu \mathrm{L}$ deionized water $\left(\mathrm{ddH}_{2} \mathrm{O}\right)\left(4{ }^{\circ} \mathrm{C}\right)$ and vortex for $30 \mathrm{~s}$, then added $100 \mathrm{mg}$ glass beads. Placed the tubes into liquid nitrogen for $5 \mathrm{~min}$ and thawed at roomtemperature, then put tubes in the high flux organization grinding apparatus, $70 \mathrm{~Hz}$ for $2 \mathrm{~min}$, repeated twice, centrifuged for 10 min at $13000 \mathrm{~g}\left(4^{\circ} \mathrm{C}\right)$, and transfered supernatant into a new centrifuge tube. Samples were blow-dried by vacuum concentration. Chromatographic separation was carried out in the Shimadzu LC-30A system equipped with ACQUITY UPLC ${ }^{\circ}$ HSS T3 $(150 \times 2.1 \mathrm{~mm}, 1.8 \mu \mathrm{m}$, Waters) column, with a column temperature of $40^{\circ} \mathrm{C}$. Gradient elution of the analytes was carried out with solvent A containing $0.1 \%$ formic acid in water and solvent $B$ containing acetonitrile, at a flow rate of $0.3 \mathrm{~mL} /$ min. After equilibration, $5 \mu \mathrm{L}$ of sample was injected into LC column, followed by an increasing linear gradient of solvent B (v/v): 0 0.5 min, 2\% B; 0.5 9 min, $2 \%$ $50 \%$ B; $9 \sim 12 \mathrm{~min}, 50 \% \sim 98 \% \mathrm{~B} ; 12 \sim 13 \mathrm{~min}, 98 \% \mathrm{~B}$; 13 14 min, 98\% 2\% B; 14 15 min, 2\%.

Mass spectrometry (MS) analysis was executed in an electrospray ionization mode by using AB SCIEX TripleTOF $^{\mathrm{m}} 5600$ System. The optimization of the operating parameters were achieved as follows: spray voltage, $5500 \mathrm{~V}$ (positive), $4500 \mathrm{~V}$ (negative); nebulizer gas (NEB), 50 psi; auxiliary gas (AUX), 50 psi; curtain gas (CUR), 35 psi; source temperature, $500^{\circ} \mathrm{C}$. Full-scan MS analysis was performed over the mass range of $\mathrm{m} / \mathrm{z} 100$ 1500 , with a collision energy of $45 \mathrm{eV}$.

Metabolites were characterized by comparisons with reference standards or MS/MS fragment information obtained from the Human Metabolome Database (HMDB) (http://www.hmdb.ca), the Metlin Database (http:// metlin.scripps.edu), the massbank Database (http://www. massbank.jp/), the LipidMaps Database (http://www. lipidmaps.org) or the mzclound Database (https://www. mzcloud.org). We used IDA (Information Dependant Acquistion) and selected the signal intensity of the first 8 ions in the parent ion for secondary fragmentation (Additional file 8: Figure S1).

\section{UPLC-MS (high resolution ultra-performance liquid chromatography-mass spectrometry) determination of amino acids}

An equimolar standard mixture of all 20 amino acids(L-glycine, L-sarcosine, L-alanine, L-valine, L-proline, L-threonine, L-isoleucine, L-leucine, L-ornithine, L-methionine, L-histidine, L-phenylalanine, L-arginine, L-tyrosine, L-aspartic acid, L-tryptophan, 4-aminobutyric acid, L-serine, L-lysine, L-glutamic acid) was prepared, the final concentration was $0.2 \mu \mathrm{g} / \mathrm{mL}, 0.5 \mu \mathrm{g} / \mathrm{mL}, 1 \mu \mathrm{g} / \mathrm{mL}, 2$ $\mu \mathrm{g} / \mathrm{mL}, 5 \mu \mathrm{g} / \mathrm{mL}, 10 \mu \mathrm{g} / \mathrm{mL}, 20 \mu \mathrm{g} / \mathrm{mL}$ and $50 \mu \mathrm{g} / \mathrm{mL}$.

$100 \mathrm{mg}$ of bacteria pellets was ground into fine powder in liquid nitrogen, amino acids were extracted with 1 $\mathrm{mL} \mathrm{HCl}$ overnight. The tubes were centrifuged at 12000 rpm for $5 \mathrm{~min}$ to collecte the supernatant. $100 \mu \mathrm{L}$ of isotope-labelled amino acids (Alanine - $\mathrm{d} 4$ ) internal 
standard was then added to the tube and blended, and drying with a moderate nitrogen gas stream. For derivatisation, $60 \mu \mathrm{L}$ of derivatisation reagent [hydrochloric acid/n-butyl alcohol (1: 3, v/v)] was added into the mixture and reacted for $15 \mathrm{~min}$ at $65{ }^{\circ} \mathrm{C}$. Then, the sample was separated and analysed by UPLC-MS.

The ACQUITY UPLC System equipped with a $1.7 \mu \mathrm{m}$ C18 column (ACQUITY UPLC BEH, $2.1 \times 100 \mathrm{~mm}$, Waters) set at $40^{\circ} \mathrm{C}$ was used for chromatographic separation. Gradient elution of the analytes was implemented with solvent A containing $0.1 \%$ formic acid and $0.1 \%$ heptafluorobutyric acid in acetonitrile, solvent B containing $0.1 \%$ formic acid in water, at a flow rate of 0.25 $\mathrm{mL} / \mathrm{min}$. Five microliter of sample was injected following equilibration. An increasing linear gradient of solvent A (v/v) was used as follows: $0 \sim 1.5 \mathrm{~min}, 5 \% \mathrm{~A} ; 1.5 \sim 2 \mathrm{~min}$, 5 20\% A; 2 7 min, 20 30\% A; 7 8.5 min, 30 98\% A; 8.5 10.5 min, 98\% A; 10.5 11 min, 98 5\% A; 11 12.5 $\min , 5 \% \mathrm{~A}$.

The ESI source was used in positive mode by multiple reaction monitoring (MRM) mode. The following conditions of detection were applied: ion source capillary voltage, $3200 \mathrm{~V}$; cone voltage, $20 \mathrm{~V}$; desolvation temperature, $380{ }^{\circ} \mathrm{C}$.

\section{Statistical analysis}

All experiments were performed at least in biological triplicate and the results are presented as the mean \pm standard deviation (SD). Values were considered to be statistically significant when $P$-value was $<0.05$ and the statistical significance of the observed differences was assessed with one way analysis of variance (one-way ANOVA).

\section{Additional files}

Additional file 1: Table S1. The complete list of differentially expressed genes in control and $\mathrm{V}_{\mathrm{B} 1}$-treated samples. (XLS $111 \mathrm{~kb}$ )

Additional file 2: Table S2. The change fold of genes listed in the manuscript. (XLSX $11 \mathrm{~kb})$

Additional file 3: Table S3. The primers used in this study. (DOCX $22 \mathrm{~kb}$ )

Additional file 4: Table S4. The complete list of differentially produced metabolites in control and $V_{B 1}$-treated samples. (XLSX $26 \mathrm{~kb}$ )

Additional file 5: Table S5. The complete list of detected amino acids in control and $V_{B 1}$-treated samples. (XLSX $23 \mathrm{~kb}$ )

Additional file 6: Table S6. The associated KEGG analysis of transcriptomics and metabolomics in control and $V_{B 1}$-treated samples. (XLS $44 \mathrm{~kb}$ )

Additional file 7: Table S7. The homologous genes between M. bovis BCG and M. tuberculosis H37Rv. (XLS $1840 \mathrm{~kb}$ )

Additional file 8: Figure S1. Fragmentation spectrum for LC-MS. (DOCX $1592 \mathrm{~kb})$

\section{Abbreviations}

ADP: Adenosine diphosphate; FDR: False discovery rate; GTP: Guanosine triphosphate; INH: Isoniazid; MDR: Multidrug resistant; MS: Mass spectrometry;
Mtb: Mycobacterium tuberculosis; NAD: Adenine dinucleotide; OD: Optical density; PCR: Polymerase chain reaction; PFK: Phosphofructokinase; qRTPCR: Quantitative real-time PCR; RIF: Rifampicin; SD: Standard deviation; TG: Triacylglycerol; TGS: Triacylglycerol synthase; ThDP: Thiamin diphosphate; ups: Universal stress proteins; $V_{A}$ : Vitamin $A_{;} V_{B 1}$ : Vitamin $B_{1} ; V_{c}$ : Vitamin $C_{i}$ $V_{D}$ : Vitamin D

\section{Acknowledgements}

Not applicable.

Funding

The work was financially supported by National Key R\&D Program of China (Grant No. 2017YFD0500906), the National Natural Science Foundation of China (Grant No.31873014 and 31772767) and National Key R\&D Program of China (Grant No. 2017YFD0500304) for data interpretation and design of the study.

\section{Availability of data and materials}

The transcriptome analysis data are available in the GEO repository under accession number GSE114949 and the link is https://www.ncbi.nlm.nih.gov/ geo/query/acc.cgi?acc=GSE1 14949

\section{Authors' contributions}

NNS performed the experiments and wrote the manuscript; ZLL performed the experiment including qRT-PCR; ZYC, LPC, YYC, GHD, ZL and HL did some transcriptome analysis;: SGL designed the experiment and corrected the manuscript. All authors read and approved the final manuscript.

Ethics approval and consent to participate

Not applicable.

Consent for publication

Not applicable.

Competing interests

The authors declare that they have no competing interests.

\section{Publisher's Note}

Springer Nature remains neutral with regard to jurisdictional claims in published maps and institutional affiliations.

Received: 26 October 2018 Accepted: 14 May 2019

Published online: 22 May 2019

\section{References}

1. Betts JC, Lukey PT, Robb LC, McAdam RA, Duncan K. Evaluation of a nutrient starvation model of Mycobacterium tuberculosis persistence by gene and protein expression profiling. Mol Microbiol. 2002;43(3):717-31.

2. Schnappinger D, Ehrt S, Voskuil MI, Liu Y, Mangan JA, Monahan IM, Dolganov G, Efron B, Butcher PD, Nathan C, et al. Transcriptional adaptation of Mycobacterium tuberculosis within macrophages: insights into the phagosomal environment. J Exp Med. 2003;198(5):693-704.

3. Fisher MA, Plikaytis BB, Shinnick TM. Microarray analysis of the Mycobacterium tuberculosis transcriptional response to the acidic conditions found in phagosomes. J Bacteriol. 2002;184(14):4025-32.

4. Li XJ, Wu J, Han J, Hu YF, Mi KX. Distinct responses of Mycobacterium smegmatis to exposure to low and high levels of hydrogen peroxide. PLoS One. 2015;10(7)

5. Sikri K, Batra SD, Nandi M, Kumari P, Taneja NK, Tyagi JS. The pleiotropic transcriptional response of Mycobacterium tuberculosis to vitamin C is robust and overlaps with the bacterial response to multiple intracellular stresses. Microbiol-Sgm. 2015;161:739-53.

6. Cappelli G, Volpe E, Grassi M, Liseo B, Colizzi V, Mariani F. Profiling of Mycobacterium tuberculosis gene expression during human macrophage infection: upregulation of the alternative sigma factor $G$, a group of transcriptional regulators, and proteins with unknown function. Res Microbiol. 2006;157(5):445-55.

7. Rachman H, Strong M, Schaible U, Schuchhardt J, Hagens K, Mollenkopf $H$, Eisenberg D, Kaufmann SHE. Mycobacterium tuberculosis gene expression profiling within the context of protein networks. Microbes Infect. 2006;8(3):747-57. 
8. Tailleux L, Waddell SJ, Pelizzola M, Mortellaro A, Withers M, Tanne A, Castagnoli PR, Gicquel B, Stoker NG, Butcher PD, et al. Probing host pathogen cross-talk by transcriptional profiling of both Mycobacterium tuberculosis and infected human dendritic cells and macrophages. PLoS One. 2008;3(1).

9. Warner DF. Mycobacterium tuberculosis Metabolism. Cold Spring Harbor perspectives in medicine. 2015;5(4).

10. Ehrt S, Rhee K. Mycobacterium tuberculosis metabolism and host interaction: mysteries and paradoxes. Curr Top Microbiol Immunol. 2013; 374:163-88.

11. Bi J, Wang $H$, Xie J. Comparative genomics of $N A D(P)$ biosynthesis and novel antibiotic drug targets. J Cell Physiol. 2011;226(2):331-40.

12. Salaemae W, Azhar A, Booker GW, Polyak SW. Biotin biosynthesis in Mycobacterium tuberculosis: physiology, biochemistry and molecular intervention. Protein \& cell. 2011;2(9):691-5.

13. Hatzios SK, Bertozzi CR. The regulation of sulfur metabolism in Mycobacterium tuberculosis. PLoS Pathog. 2011;7(7):e1002036.

14. Amon J, Titgemeyer F, Burkovski A. A genomic view on nitrogen metabolism and nitrogen control in mycobacteria. J Mol Microbiol Biotechnol. 2009;17(1):20-9.

15. Shin JH, Yang JY, Jeon BY, Yoon YJ, Cho SN, Kang YH, Ryu DH, Hwang GS. H-1 NMR-based Metabolomic profiling in mice infected with Mycobacterium tuberculosis. J Proteome Res. 2011;10(5):2238-47.

16. Somashekar BS, Amin AG, Tripathi P, MacKinnon N, Rithner CD, Shanley CA, Basaraba R, Henao-Tamayo M, Kato-Maeda M, Ramamoorthy A, et al. Metabolomic signatures in Guinea pigs infected with epidemic-associated W-Beijing strains of Mycobacterium tuberculosis. J Proteome Res. 2012;11(10): 4873-84.

17. Settembre E, Begley TP, Ealick SE. Structural biology of enzymes of the thiamin biosynthesis pathway. Curr Opin Struc Biol. 2003;13(6):739-47.

18. Begley TP, Downs DM, Ealick SE, McLafferty FW, Van Loon APGM, Taylor S, Campobasso N, Chiu HJ, Kinsland C, Reddick JJ, et al. Thiamin biosynthesis in prokaryotes. Arch Microbiol. 1999;171(5):293-300.

19. Pohl M, Sprenger GA, Muller M. A new perspective on thiamine catalysis. Curr Opin Biotech. 2004;15(4):335-42.

20. Hosomi K, Kunisawa J. The specific roles of vitamins in the regulation of Immunosurveillance and maintenance of immunologic homeostasis in the gut. Immune network. 2017;17(1):13-9.

21. Manzetti S, Zhang J, van der Spoel D. Thiamin function, metabolism, uptake, and transport. Biochemistry. 2014;53(5):821-35.

22. Gibson GE, Blass JP. Thiamine-dependent processes and treatment strategies in neurodegeneration. Antioxid Redox Signal. 2007;9(10):1605-19.

23. Butterworth RF, Besnard AM. Thiamine-dependent enzyme changes in temporal cortex of patients with Alzheimer's disease. Metab Brain Dis. 1990; 5(4):179-84

24. Huang HM, Chen HL, Gibson GE. Thiamine and oxidants interact to modify cellular calcium stores. Neurochem Res. 2010;35(12):2107-16.

25. Gangolf M, Wins P, Thiry M, El Moualij B, Bettendorff L. Thiamine triphosphate synthesis in rat brain occurs in mitochondria and is coupled to the respiratory chain. J Biol Chem. 2010;285(1):583-94.

26. Syal K, Chakraborty S, Bhattacharyya R, Banerjee D. Combined inhalation and oral supplementation of vitamin a and vitamin D: a possible prevention and therapy for tuberculosis. Med Hypotheses. 2015:84(3):199-203.

27. Dini C, Bianchi A. The potential role of vitamin D for prevention and treatment of tuberculosis and infectious diseases. Ann I Super Sanita. 2012; 48(3):319-27.

28. Vilcheze C, Hartman T, Weinrick B, Jacobs WR. Mycobacterium tuberculosis is extraordinarily sensitive to killing by a vitamin C-induced Fenton reaction. Nat Commun. 2013;4.

29. Riaz H, Riaz I, Abir T, Badshah M, Milton A. Vitamin D as a supplementary agent in the treatment of pulmonary tuberculosis: a systematic review and meta-analysis of randomized controlled trials. Eur Respir J. 2013:42.

30. He W, Hu S, Du X, Wen Q, Zhong XP, Zhou X, Zhou C, Xiong W, Gao Y, Zhang $S$, et al. Vitamin B5 reduces bacterial growth via regulating innate immunity and adaptive immunity in mice infected with Mycobacterium tuberculosis. Front Immunol. 2018:9:365.

31. Song N, Cui Y, Li Z, Chen L, Liu S. New targets and cofactors for the transcription factor LrpA from Mycobacterium tuberculosis. DNA Cell Biol. 2016;35(4):167-76.

32. Luong K, Nguyen LT. Impact of vitamin D in the treatment of tuberculosis. Am J Med Sci. 2011;341(6):493-8.
33. Huang QQ, Abdalla AE, Xie JP. Phylogenomics of Mycobacterium nitrate reductase operon. Curr Microbiol. 2015;71(1):121-8.

34. Weber I, Fritz C, Ruttkowski S, Kreft A, Bange FC. Anaerobic nitrate reductase (narGHJI) activity of Mycobacterium bovis BCG in vitro and its contribution to virulence in immunodeficient mice. Mol Microbiol. 2000;35(5):1017-25.

35. Gao CH, Yang M, He ZG. Characterization of a novel ArsR-like regulator encoded by Rv2034 in Mycobacterium tuberculosis. PLoS One. 2012;7(4): e36255.

36. Commandeur S, van Meijgaarden KE, Prins C, Pichugin AV, Dijkman K, van den Eeden SJF, Friggen AH, Franken KLMC, Dolganov G, Kramnik I, et al. An unbiased genome-wide Mycobacterium tuberculosis gene expression approach to discover antigens targeted by human T cells expressed during pulmonary infection. J Immunol. 2013;190(4):1659-71.

37. Commandeur S, Coppola M, Dijkman K, Friggen AH, van Meijgaarden KE, Van den Eeden SJF, Wilson L, Van der Ploeg-van Schip JJ, Franken KLMC, Geluk A, et al. Clonal analysis of the T-cell response to in vivo expressed Mycobacterium tuberculosis protein Rv2034, using a CD154 expression based T-cell cloning method. PLoS One. 2014;9(6).

38. Kendall SL, Withers M, Soffair CN, Moreland NJ, Gurcha S, Sidders B, Frita R, ten Bokum A, Besra GS, Lott JS, et al. A highly conserved transcriptional repressor controls a large regulon involved in lipid degradation in Mycobacterium smegmatis and Mycobacterium tuberculosis. Mol Microbiol. 2007;65(3):684-99.

39. Gomez RL, Jose L, Ramachandran R, Raghunandanan S, Muralikrishnan B, Johnson JB, Sivakumar KC, Mundayoor S, Kumar RA. The multiple stress responsive transcriptional regulator Rv3334 of Mycobacterium tuberculosis is an autorepressor and a positive regulator of kstR. FEBS J. 2016;283(16):3056-71.

40. Galagan JE, Minch K, Peterson M, Lyubetskaya A, Azizi E, Sweet L, Gomes A, Rustad T, Dolganov G, Glotova I, et al. The Mycobacterium tuberculosis regulatory network and hypoxia. Nature. 2013;499(7457):178-83.

41. Black GF, Thiel BA, Ota MO, Parida SK, Adegbola R, Boom WH, Dockrell HM, Franken KLMC, Friggen AH, Hill PC, et al. Immunogenicity of novel DosR regulon-encoded candidate antigens of Mycobacterium tuberculosis in three high-burden populations in Africa. Clin Vaccine Immunol. 2009; 16(8):1203-12.

42. Dasgupta N, Kapur V, Singh KK, Das TK, Sachdeva S, Jyothisri K, Tyagi JS. Characterization of a two component system, devR-devS, of Mycobacterium tuberculosis. Tubercle Lung Dis. 2000;80(3):141-59.

43. Park HD, Guinn KM, Harrell MI, Liao R, Voskuil MI, Tompa M, Schoolnik GK, Sherman DR. Rv3133c/dosR is a transcription factor that mediates the hypoxic response of Mycobacterium tuberculosis. Mol Microbiol. 2003;48(3):833-43.

44. Voskuil MI, Schnappinger D, Visconti KC, Harrell MI, Dolganov GM, Sherman DR, Schoolnik GK. Inhibition of respiration by nitric oxide induces a Mycobacterium tuberculosis dormancy program. J Exp Med. 2003;198(5):705-13.

45. Shiloh MU, Manzanillo P, Cox JS. Mycobacterium tuberculosis senses host-derived carbon monoxide during macrophage infection. Cell Host Microbe. 2008;3(5):323-30.

46. Taneja NK, Dhingra S, Mittal A, Naresh M, Tyagi JS. Mycobacterium tuberculosis transcriptional adaptation, growth arrest and dormancy phenotype development is triggered by vitamin C. PLoS One. 2010;5(5).

47. Chauhan S, Sharma D, Singh A, Surolia A, Tyagi JS. Comprehensive insights into Mycobacterium tuberculosis DevR (DosR) regulon activation switch. Nucleic Acids Res. 2011;39(17):7400-14.

48. Leistikow RL, Morton RA, Bartek IL, Frimpong I, Wagner K, Voskuil MI. The Mycobacterium tuberculosis DosR regulon assists in metabolic homeostasis and enables rapid recovery from nonrespiring dormancy. J Bacteriol. 2010; 192(6):1662-70

49. Stallings CL, Stephanou NC, Chu L, Hochschild A, Nickels BE, Glickman MS. CarD is an essential regulator of rRNA transcription required for Mycobacterium tuberculosis persistence. Cell. 2009;138(1):146-59.

50. Singh A, Crossman DK, Mai D, Guidry L, Voskuil Ml, Renfrow MB, Steyn AJC. Mycobacterium tuberculosis WhiB3 maintains redox homeostasis by regulating virulence lipid anabolism to modulate macrophage response. PLOS Pathog. 2009;5(8).

51. Geiman DE, Raghunand TR, Agarwal N, Bishai WR. Differential gene expression in response to exposure to antimycobacterial agents and other stress conditions among seven Mycobacterium tuberculosis whiBlike genes. Antimicrob Agents Ch. 2006;50(8):2836-41. 
52. Mishra A, Sarkar D. Qualitative and quantitative proteomic analysis of vitamin C induced changes in Mycobacterium smegmatis. Front Microbiol. 2015;6.

53. Larsson C, Luna B, Ammerman NC, Maiga M, Agarwal N, Bishai WR. Gene expression of Mycobacterium tuberculosis putative transcription factors whiB1-7 in redox environments. PLoS One. 2012;7(7).

54. Chen ZK, Hu YB, Cumming BM, Lu P, Feng LP, Deng JY, Steyn AJC, Chen SY. Mycobacterial WhiB6 differentially regulates ESX-1 and the dos regulon to modulate granuloma formation and virulence in zebrafish. Cell Rep. 2016; 16(9):2512-24.

55. Davis JM, Ramakrishnan L. The role of the granuloma in expansion and dissemination of early tuberculous infection. Cell. 2009;136(1):37-49.

56. Ang MLT, Rahim SZZ, Shui GH, Dianiskova P, Madacki J, Lin WW, Koh VHQ, Gomez JMM, Sudarkodi S, Bendt A et al: An ethA-ethR-deficient Mycobacterium bovis BCG mutant displays increased adherence to mammalian cells and greater persistence In Vivo, which correlate with altered mycolic acid composition (vol 82, pg 1850, 2014). Infect Immun 2015, 83(2):846

57. Bolla JR, Do SV, Long F, Dai L, Su CC, Lei HT, Chen X, Gerkey JE, Murphy DC, Rajashankar KR, et al. Structural and functional analysis of the transcriptional regulator Rv3066 of Mycobacterium tuberculosis. Nucleic Acids Res. 2012; 40(18):9340-55.

58. De Rossi E, Branzoni M, Cantoni R, Milano A, Riccardi G, Ciferri O. mmr, a Mycobacterium tuberculosis gene conferring resistance to small cationic dyes and inhibitors. J Bacteriol. 1998;180(22):6068-71.

59. Dutta NK, Mehra S, Kaushal D. A Mycobacterium tuberculosis sigma factor network responds to cell-envelope damage by the promising antimycobacterial Thioridazine. PLoS One. 2010;5(4).

60. Gong CL, Martins A, Bongiorno P, Glickman M, Shuman S. Biochemical and genetic analysis of the four DNA ligases of mycobacteria. J Biol Chem. 2004; 279(20):20594-606.

61. Kumar A, Majid M, Kunisch R, Rani PS, Qureshi IA, Lewin A, Hasnain SE, Ahmed N. Mycobacterium tuberculosis DosR regulon gene Rv0079 encodes a putative, 'Dormancy associated translation inhibitor (DATIN). PLoS One. 2012;7(6).

62. Mishra S. Function prediction of Rv0079, a hypothetical Mycobacterium tuberculosis DosR regulon protein. J Biomol Struct Dyn. 2009;27(3):283-91.

63. Kumar A, Lewin A, Rani PS, Qureshi IA, Devi S, Majid M, Kamal E, Marek S, Hasnain SE, Ahmed N. Dormancy associated translation inhibitor (DATIN/ Rv0079) of Mycobacterium tuberculosis interacts with TLR2 and induces proinflammatory cytokine expression. Cytokine. 2013;64(1):258-64.

64. Lindquist S, Craig EA. The heat-shock proteins. Annu Rev Genet. 1988;22: 631-77.

65. Mayhew M, da Silva AC, Martin J, Erdjument-Bromage $H$, Tempst P, Hartl FU. Protein folding in the central cavity of the GroEL-GroES chaperonin complex. Nature. 1996;379(6564):420-6.

66. Goyal K, Qamra R, Mande SC. Multiple gene duplication and rapid evolution in the groEL gene: functional implications. J Mol Evol. 2006;63(6):781-7.

67. Smollett KL, Smith KM, Kahramanoglou C, Arnvig KB, Buxton RS, Davis EO. Global analysis of the regulon of the transcriptional repressor LexA, a key component of SOS response in Mycobacterium tuberculosis. J Biol Chem. 2012;287(26):22004-14.

68. Miner MD, Chang JC, Pandey AK, Sassetti CM, Sherman DR. Role of cholesterol in Mycobacterium tuberculosis infection. Indian J Exp Biol. 2009; 47(6):407-11.

69. Nesbitt NM, Yang XX, Fontan P, Kolesnikova I, Smith I, Sampson NS, Dubnau E. A Thiolase of Mycobacterium tuberculosis is required for virulence and production of androstenedione and Androstadienedione from cholesterol. Infect Immun. 2010;78(1):275-82.

70. Carroll P, Parish T. Deletion of cyp125 confers increased sensitivity to azoles in Mycobacterium tuberculosis. PLoS One. 2015;10(7).

71. Sirakova TD, Dubey VS, Deb C, Daniel J, Korotkova TA, Abomoelak B, Kolattukudy PE. Identification of a diacylglycerol acyltransferase gene involved in accumulation of triacylglycerol in Mycobacterium tuberculosis under stress. Microbiol-Sgm. 2006;152:2717-25.

72. Phong WY, Lin WW, Rao SPS, Dick T, Alonso S, Pethe K. Characterization of phosphofructokinase activity in Mycobacterium tuberculosis reveals that a functional glycolytic carbon flow is necessary to limit the accumulation of toxic metabolic intermediates under hypoxia. PLoS One. 2013;8(2).

73. Wagner D, Maser J, Lai B, Cai ZH, Barry CE, Bentrup KHZ, Russell DG, Bermudez LE. Elemental analysis of Mycobacterium avium-, Mycobacterium tuberculosis-, and Mycobacterium smegmatis-containing phagosomes indicates pathogen-induced microenvironments within the host cell's endosomal system. J Immunol. 2005;174(3):1491-500.

74. Wardman P, Candeias LP. Fenton chemistry: an introduction. Radiat Res. 1996;145(5):523-31.

75. Macomber L, Imlay JA. The iron-sulfur clusters of dehydratases are primary intracellular targets of copper toxicity. P Natl Acad Sci USA. 2009;106(20): 8344-9.

76. Ramirez-Cardenas L, Costa NMB, Reis FP. Copper-iron metabolism interaction in rats. Nutr Res. 2005;25(1):79-92.

77. Marcus SA, Sidiropoulos SW, Steinberg H, Talaat AM. CsoR is essential for maintaining copper homeostasis in Mycobacterium tuberculosis. PLoS One. 2016;11(3).

78. Liu T, Ramesh A, Ma Z, Ward SK, Zhang LM, George GN, Talaat AM, Sacchettini JC, Giedroc DP. CsoR is a novel Mycobacterium tuberculosis copper-sensing transcriptional regulator. Nat Chem Biol. 2007;3(1):60-8.

79. Ward SK, Abomoelak B, Hoye EA, Steinberg H, Talaat AM. CtpV: a putative copper exporter required for full virulence of Mycobacterium tuberculosis. Mol Microbiol. 2010;77(5):1096-110.

80. Braibant M, Gilot P, Content J. The ATP binding cassette (ABC) transport systems of Mycobacterium tuberculosis. FEMS Microbiol Rev. 2000;24(4): 449-67.

81. Green RM, Seth A, Connell ND. A peptide permease mutant of Mycobacterium bovis BCG resistant to the toxic peptides glutathione and Snitrosoglutathione. Infect Immun. 2000;68(2):429-36.

82. Dasgupta A, Sureka K, Mitra D, Saha B, Sanyal S, Das AK, Chakrabarti P, Jackson M, Gicquel B, Kundu M, et al. An oligopeptide transporter of Mycobacterium tuberculosis regulates cytokine release and apoptosis of infected macrophages. PLoS One. 2010;5(8).

83. Flores-Valdez MA, Morris RP, Laval F, Daffe M, Schoolnik GK. Mycobacterium tuberculosis modulates its cell surface via an oligopeptide permease (Opp) transport system. FASEB J. 2009;23(12):4091-104.

84. Griffin JE, Gawronski JD, DeJesus MA, loerger TR, Akerley BJ, Sassetti CM. High-resolution phenotypic profiling defines genes essential for mycobacterial growth and cholesterol catabolism. PLoS Pathog. 2011;7(9).

85. Fullam E, Prokes I, Futterer K, Besra GS. Structural and functional analysis of the solute-binding protein UspC from Mycobacterium tuberculosis that is specific for amino sugars. Open Biol. 2016;6(6).

86. Smith I. Mycobacterium tuberculosis pathogenesis and molecular determinants of virulence. Clin Microbiol Rev. 2003;16(3):463.

87. Gande R, Gibson KJC, Brown AK, Krumbach K, Dover LG, Sahm H, Shioyama S, Oikawa T, Besra GS, Eggeling L. Acyl-CoA carboxylases (accD2 and accD3), together with a unique polyketide synthase (cg-pks), are key to mycolic acid biosynthesis in corynebacterianeae such as Corynebacterium glutamicum and Mycobacterium tuberculosis. Biol Chem. 2004;279(43):44847-57.

88. Singhal N, Sharma P, Kumar M, Joshi B, Bisht D. Analysis of intracellular expressed proteins of Mycobacterium tuberculosis clinical isolates. Proteome Sci. 2012;10.

89. Cole ST, Brosch R, Parkhill J, Garnier T, Churcher C, Harris D, Gordon SV, Eiglmeier K, Gas S, Barry CE, et al. Deciphering the biology of Mycobacterium tuberculosis from the complete genome sequence (vol 393, pg 537, 1998). Nature. 1998;396(6707):190-8.

90. Ramakrishnan L, Federspiel NA, Falkow S. Granuloma-specific expression of Mycobacterium virulence proteins from the glycine-rich PE-PGRS family. Science. 2000;288(5470):1436-9.

91. Sampson SL, Lukey P, Warren RM, van Helden PD, Richardson M, Everett MJ. Expression, characterization and subcellular localization of the Mycobacterium tuberculosis PPE gene Rv1917c. Tuberculosis. 2001;81(5-6):305-17.

92. Sturgill-Koszycki S, Schlesinger PH, Chakraborty P, Haddix PL, Collins HL, Fok AK, Allen RD, Gluck SL, Heuser J, Russell DG. Lack of acidification in Mycobacterium phagosomes produced by exclusion of the vesicular proton-ATPase. Science. 1994;263(5147):678-81.

93. Li YJ, Miltner E, Wu M, Petrofsky M, Bermudez LE. A Mycobacterium avium PPE gene is associated with the ability of the bacterium to grow in macrophages and virulence in mice. Cell Microbiol. 2005;7(4):539-48.

94. Zhang HM, Wang JL, Lei JQ, Zhang M, Yang YP, Chen Y, Wang HH. PPE protein (Rv3425) from DNA segment RD11 of Mycobacterium tuberculosis: a potential B-cell antigen used for serological diagnosis to distinguish vaccinated controls from tuberculosis patients. Clin Microbiol Infec. 2007; 13(2):139-45. 
95. Xu Y, Yang E, Wang J, Li R, Li G, Liu G, Song N, Huang Q, Kong C, Wang H. Prime-boost bacillus Calmette-Guerin vaccination with lentivirus-vectored and DNA-based vaccines expressing antigens Ag85B and Rv3425 improves protective efficacy against Mycobacterium tuberculosis in mice. Immunology. 2014;143(2):277-86.

96. Chevrier D, Casademont I, Guesdon JL. Cloning of a gene from Mycobacterium tuberculosis coding for a hypothetical $27 \mathrm{kDa}$ protein and its use for the specific PCR identification of these mycobacteria. Mol Cell Probes. 2000;14(4):241-8.

97. Le Moigne V, Robreau G, Borot C, Guesdon JL, Mahana W. Expression, immunochemical characterization and localization of the Mycobacterium tuberculosis protein p27. Tuberculosis. 2005;85(4):213-9.

98. Le Moigne V, Le Moigne D, Mahana W. Antibody response to Mycobacterium tuberculosis p27-PPE36 antigen in sera of pulmonary tuberculosis patients. Tuberculosis. 2013;93(2):189-91.

99. Bretl DJ, He H, Demetriadou C, White MJ, Penoske RM, Salzman NH, Zahrt TC. MprA and DosR coregulate a Mycobacterium tuberculosis virulence operon encoding Rv1813C and Rv1812C. Infect Immun. 2012;80(9):3018-33.

100. Hingley-Wilson SM, Lougheed KEA, Ferguson K, Leiva S, Williams HD. Individual Mycobacterium tuberculosis universal stress protein homologues are dispensable in vitro. Tuberculosis. 2010;90(4):236-44.

101. Pedley AM, Benkovic SJ. A new view into the regulation of purine metabolism: the Purinosome. Trends Biochem Sci. 2017:42(2):141-54.

102. Lu'o'ng KV, Nguyen LT. The role of thiamine in cancer: possible genetic and cellular signaling mechanisms. Cancer genomics proteomics. 2013;10(4): 169-85.

103. Khanh VQL, Lan THN. Thiamine and Parkinson's disease. J Neurol Sci. 2012; 316(1-2):1-8.

104. Lu'o'ng KVQ, Nguyen LTH. The role of thiamine in HIV infection. Int J Infect Dis. 2013;17(4):E221-7.

105. Ren WK, Rajendran R, Zhao YY, Tan B, Wu GY, Bazer FW, Zhu GQ, Peng YY, Huang XS, Deng JP, et al. Amino acids as mediators of metabolic cross talk between host and pathogen. Front Immunol. 2018;9.

106. Gouzy A, Larrouy-Maumus G, Wu TD, Peixoto A, Levillain F, Lugo-Villarino G, Guerquin-Kern JL, de Carvalho LPS, Poquet Y, Neyrolles O. Mycobacterium tuberculosis nitrogen assimilation and host colonization require aspartate. Nat Chem Biol. 2013;9(11):674.

107. Gouzy A, Poquet $Y$, Neyrolles O. A central role for aspartate in Mycobacterium tuberculosis physiology and virulence. Front Cell Infect Mi. 2013;3.

108. Gouzy A, Larrouy-Maumus G, Bottai D, Levillain F, Dumas A, Wallach JB, Caire-Brandli I, de Chastellier C, Wu TD, Poincloux R, et al. Mycobacterium tuberculosis exploits asparagine to assimilate nitrogen and resist acid stress during infection. PLoS Pathog. 2014;10(2).

109. Lyon RH, Hall WH, Costas-Martinez C. Utilization of amino acids during growth of Mycobacterium tuberculosis in rotary cultures. Infect Immun. 1970; 1(6):513-20.

110. Reitzer L. Biosynthesis of glutamate, aspartate, asparagine, L-alanine, and Dalanine. EcoSal Plus. 2004;1(1).

111. Chen JM, Alexander DC, Behr MA, Liu J. Mycobacterium bovis BCG vaccines exhibit defects in alanine and serine catabolism. Infect Immun. 2003;71(2):708-16.

112. Wu G. Amino acids: metabolism, functions, and nutrition. Amino Acids. 2009;37(1):1-17.

113. Ren W, Yin J, Duan J, Liu G, Tan B, Yang G, Wu G, Bazer FW, Peng Y, Yin Y. mTORC1 signaling and IL-17 expression: defining pathways and possible therapeutic targets. Eur J Immunol. 2016;46(2):291-9.

114. Ren W, Liu G, Chen S, Yin J, Wang J, Tan B, Wu G, Bazer FW, Peng Y, Li T, et al. Melatonin signaling in T cells: functions and applications. J Pineal Res. 2017;62(3).

115. Ren W, Liu G, Yin J, Tan B, Wu G, Bazer FW, Peng Y, Yin Y. Amino-acid transporters in T-cell activation and differentiation. Cell Death Dis. 2017; 8(5):e2757.

116. Fang Y, French J, Zhao H, Benkovic S. G-protein-coupled receptor regulation of de novo purine biosynthesis: a novel druggable mechanism. Biotechnol Genet Eng Rev. 2013;29:31-48.

117. Schmidt H, Siems WG, Grune T, Grauel EL. Concentration of purine compounds in the cerebrospinal-fluid of infants suffering from Sepsis, convulsions and hydrocephalus. J Perinat Med. 1995;23(3):167-74.

118. Jabs CM, Neglen P, Eklof B. Breakdown of adenine-nucleotides, formation of oxygen-free radicals, and early markers of cellular injury in Endotoxic-shock. Eur J Surg. 1995;161(3):147-55.
119. Jin X, Shepherd RK, Duling BR, Linden J. Inosine binds to A3 adenosine receptors and stimulates mast cell degranulation. J Clin Invest. 1997; 100(11):2849-57.

120. Markowitz CE, Spitsin S, Zimmerman V, Jacobs D, Udupa JK, Hooper DC, Koprowski $\mathrm{H}$. The treatment of multiple sclerosis with inosine. J Altern Complement Med. 2009;15(6):619-25.

121. Trapnell C, Pachter L, Salzberg SL. TopHat: discovering splice junctions with RNA-Seq. Bioinformatics. 2009;25(9):1105-11.

122. Trapnell C, Williams BA, Pertea G, Mortazavi A, Kwan G, van Baren MJ, Salzberg SL, Wold BJ, Pachter L. Transcript assembly and quantification by RNA-Seq reveals unannotated transcripts and isoform switching during cell differentiation. Nat Biotechnol. 2010;28(5):511-5.

123. Benjamini $Y$, Hochberg $Y$. Controlling the false discovery rate - a practical and powerful approach to multiple testing. J Roy Stat Soc B Met. 1995;57(1): 289-300.

124. Benjamini $Y$, Yekutieli D. The control of the false discovery rate in multiple testing under dependency. Ann Stat. 2001;29(4):1165-88.
Ready to submit your research? Choose BMC and benefit from:

- fast, convenient online submission

- thorough peer review by experienced researchers in your field

- rapid publication on acceptance

- support for research data, including large and complex data types

- gold Open Access which fosters wider collaboration and increased citations

- maximum visibility for your research: over $100 \mathrm{M}$ website views per year

At BMC, research is always in progress.

Learn more biomedcentral.com/submissions 